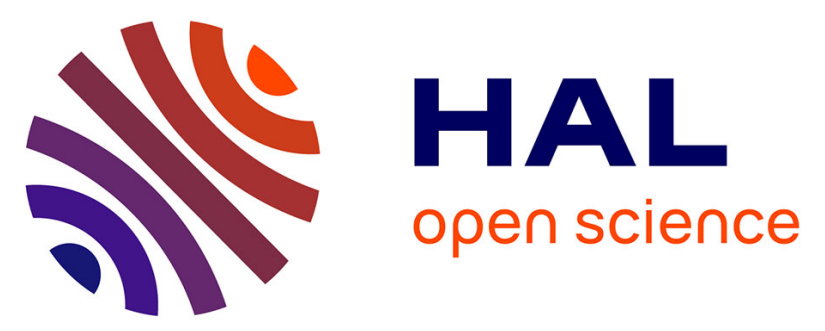

\title{
Evidence for crustal magnetic field control of ions precipitating into the upper atmosphere of Mars
}

Takuya Hara, Janet G. Luhmann, François Leblanc, Shannon M. Curry, Jasper S. Halekas, Kanako Seki, David A. Brain, Yuki Harada, James P. Mcfadden, Gina A. Dibraccio, et al.

\section{To cite this version:}

Takuya Hara, Janet G. Luhmann, François Leblanc, Shannon M. Curry, Jasper S. Halekas, et al.. Evidence for crustal magnetic field control of ions precipitating into the upper atmosphere of Mars. Journal of Geophysical Research Space Physics, 2018, 123 (10), pp.8572-8586. 10.1029/2017JA024798 . insu-01799126

\section{HAL Id: insu-01799126 \\ https://hal-insu.archives-ouvertes.fr/insu-01799126}

Submitted on 26 Nov 2020

HAL is a multi-disciplinary open access archive for the deposit and dissemination of scientific research documents, whether they are published or not. The documents may come from teaching and research institutions in France or abroad, or from public or private research centers.
L'archive ouverte pluridisciplinaire HAL, est destinée au dépôt et à la diffusion de documents scientifiques de niveau recherche, publiés ou non, émanant des établissements d'enseignement et de recherche français ou étrangers, des laboratoires publics ou privés. 


\section{Evidence for crustal magnetic field control of ions precipitating into the upper atmosphere of Mars}

Takuya Hara ${ }^{1}$, Janet G. Luhmann ${ }^{1}$, Franois Leblanc ${ }^{2}$, Shannon M. Curry ${ }^{1}$,

Jasper S. Halekas ${ }^{3}$, Kanako Seki ${ }^{4}$, David A. Brain ${ }^{5}$, Yuki Harada ${ }^{3,6}$, James

P. McFadden ${ }^{1}$, Gina A. DiBraccio ${ }^{7}$, Yasir I. J. Soobiah ${ }^{7}$, David L. Mitchell ${ }^{1}$,

Shaosui $\mathrm{Xu}^{1}$, Christian Mazelle ${ }^{8}$, and Bruce M. Jakosky ${ }^{5}$
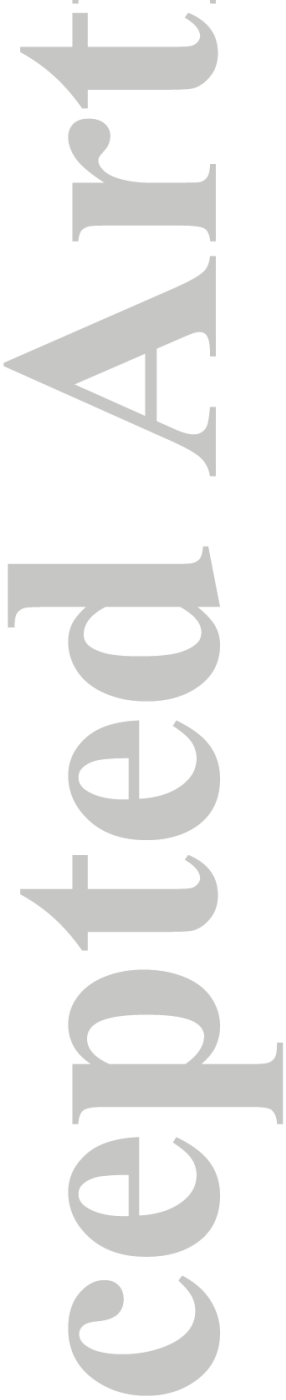

This article has been accepted for publication and undergone full peer review but has not been through the copyediting, typesetting, pagination and proofreading process, which may lead to differences between this version and the Version of Record. Please cite this article as doi: 10.1029/2017JA024798

(C)2018 American Geophysical Union. All Rights Reserved. 
Takuya Hara, hara@ssl.berkeley.edu

${ }^{1}$ Space Sciences Laboratory, University of

California Berkeley, Berkeley, California,

United States.

${ }^{2}$ LATMOS/IPSL, UPMC Univ. Paris 06 Sorbonne Universités, UVSQ, CNRS, Paris,

France.

${ }^{3}$ Department of Physics and Astronomy,

University of Iowa, Iowa City, Iowa, United

States.

${ }^{4}$ Department of Earth and Planetary

Science, Graduate School of Science,

University of Tokyo, Tokyo, Japan.

${ }^{5}$ Laboratory for Atmospheric and Space

Physics, University of Colorado Boulder,

Boulder, Colorado, United States.

${ }^{6}$ Department of Geophysics, Kyoto

University, Kyoto, Japan.

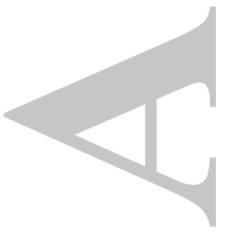

(C)2018 American Geophysical Union. All Rights Reserved. 
Abstract. We present the effects of the local magnetic field configurations on ions precipitating into the upper atmosphere of Mars using MAVEN observations. Precipitating pickup planetary heavy ions $\left(\mathrm{O}^{+}, \mathrm{O}_{2}^{+}\right.$, and $\left.\mathrm{CO}_{2}^{+}\right)$ are of particular interest in the Martian plasma environment because they potentially enhance the sputtering loss of ambient neutral particles. In addition, solar wind protons (and $\mathrm{H}^{+}$pickup ions) penetrate into the dayside atmosphere due to the direct interaction with the Martian obstacle. We present a statistical study showing that precipitating ion fluxes are typically enhanced by a factor of 2-3 under radial field configurations. We also show that the crustal fields have a shielding effect; the precipitating fluxes are significantly reduced by $\sim 50 \%$ under the strong crustal fields ( $\gtrsim 100 \mathrm{nT})$, where the local magnetic field is oriented with a more horizontal component to the surface. These trends are seen consistently regardless of ion species, as well as the observed locations including dayside/nightside, subsolar longitudes, and $\pm \boldsymbol{E}$ hemispheres in the Mars-centered Solar Electric (MSE) coordinates. In particular, the local magnetic field configurations control precipitating ions with energies lower than a few keV, while precipitating high-energy ion fluxes

${ }^{7} \mathrm{NASA}$ Goddard Space Flight Center,

Greenbelt, Maryland, United States.

${ }^{8}$ IRAP, University of Toulouse, CNRS, UPS, CNES, Toulouse, France.

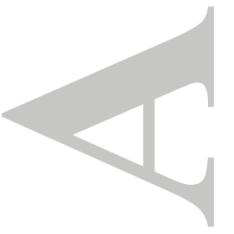

(C)2018 American Geophysical Union. All Rights Reserved. 
are likely independent of the local magnetic field configurations. Precipitating ion fluxes are known to vary by at least an order of magnitude depending on the upstream solar wind. Therefore, the local magnetic field configurations turn out to be the secondary factor in modulating precipitating ion fluxes at Mars.

\section{Keypoints:}

- Investigated the effects of the local crustal field configurations on precipitating ion fluxes into Mars

- Precipitating ion fluxes increase by a factor of 2-3 with the radial crustal fields, while decrease by half with horizontal crustal fields

- The local crustal fields consistently control precipitating ion fluxes regardless of their species and the observed location

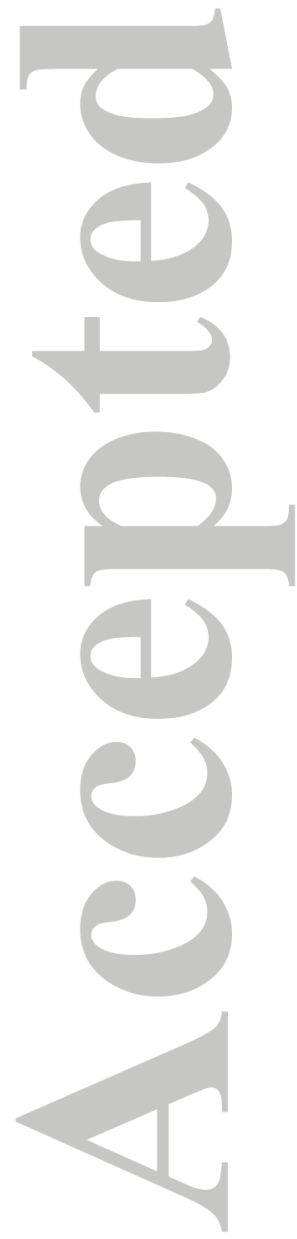




\section{Introduction}

Since Mars does not possess a global intrinsic magnetic field, the solar wind can directly interact with the Martian upper atmosphere. Planetary ions (mainly $\mathrm{O}^{+}, \mathrm{O}_{2}^{+}, \mathrm{CO}_{2}^{+}$, and $\left.\mathrm{H}^{+}\right)$at Mars can easily gain sufficient energy to escape to space in this scenario with the solar wind. When neutral particles in the Martian upper atmosphere are ionized by solar photons, charge exchange with penetrating solar wind, or solar wind electron impact [e.g., Shizgal and Arkos, 1996; Curry et al., 2013], these new-born ions are accelerated by the upstream solar wind electric field. This accelerated process is widely known as "ion pickup". While some ions gain enough energy to escape, other pickup ions precipitate back into the upper atmosphere of Mars. These precipitating heavy ions play an important role in atmospheric loss at Mars because they can transfer enough momentum and energy to the ambient neutral particles sufficient to enable their escape from the planet. This neutral escape process is referred to as "sputtering". Numerical simulations have predicted that the atmospheric loss rate due to sputtering caused by pickup heavy ions is much smaller than other atmospheric escape processes in the present epoch [e.g., Luhmann et al., 1992;

Chaufray et al., 2007]. However, sputtering could have been a major atmospheric escape channel from Mars in a past epoch due to the extreme solar EUV and solar wind conditions [e.g., Luhmann et al., 1992].

Although no direct measurements of neutral sputtered particles are currently available, Mars Atmosphere and Volatile EvolutioN (MAVEN) mission can observe the catalyst for sputtering by making measurements of precipitating ions. Previous studies have suggested that precipitating ion fluxes are highly variable by at least an order of magnitude

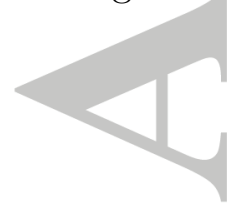

(C)2018 American Geophysical Union. All Rights Reserved. 
depending on the upstream solar wind conditions [e.g., Hara et al., 2011]. Furthermore, global maps of precipitating ions show an asymmetric pattern with respect to the upstream solar wind electric field direction, where precipitating heavy ion fluxes observed in the $-\boldsymbol{E}$ hemisphere (where the solar wind electric field is pointed toward Mars) are typically stronger than those in the $+\boldsymbol{E}$ hemisphere. Numerical simulations have predicted this hemispheric asymmetry of precipitating ions along the solar wind electric field [e.g., Luhmann and Kozyra, 1991; Chaufray et al., 2007; Fang et al., 2013; Curry et al., 2015]. Recently, such a hemispheric asymmetry of precipitating ion fluxes with respect to the direction of the upstream solar wind electric field was observationally confirmed by MAVEN [e.g., Brain et al., 2015; Hara et al., 2017a; Masunaga et al., 2017].

In addition to the precipitating pickup ion fluxes, the solar wind protons are known to penetrate into the dayside atmosphere [e.g., Dival et al., 2012, 2013; Halekas et al., 2015a, 2017; Halekas, 2017]. While they do not generally contribute to the sputtering loss, they can deposit potentially significant energy fluxes, leading to proton aurorae, similar to those occurring in the Earth magnetospheric cusp region. The amount and spatial distribution of these penetrating protons clearly depend on the magnetic field morphologies at the solar wind boundary, as well as the altitude where charge exchange neutralizes the protons.

The statistical study by Hara et al. [2017a] revealed that precipitating ion fluxes observed by MAVEN with an altitude between 200 and $350 \mathrm{~km}$ vary at least by an order of magnitude depending on either the upstream solar wind conditions (e.g., the dynamic ram pressure and strength of the interplanetary magnetic field (IMF)), or the observed locations (dayside/nightside). They conclude that gyro radii of pickup ions determined

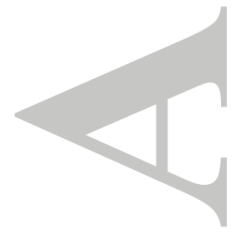

(C)2018 American Geophysical Union. All Rights Reserved. 
by upstream solar wind conditions are one of the most important factors in controlling the global ion precipitation map along the upstream solar wind electric field.

In addition to the upstream solar wind conditions and solar wind electric field, the local magnetic field configurations at Mars are another significant factor in controlling the behavior of precipitating ions of all species and energies. Mars possesses local, strong crustal magnetic fields with a strength larger than at least a few hundreds nT at $\sim 400 \mathrm{~km}$,

which are primarily distributed in the southern hemisphere with a geographic longitude of $\sim 180^{\circ}$ [e.g., Acua et al., 1998, 1999]. Thus far, a variety of plasma (or magnetospheric) dynamics have been reported in the vicinity of the Martian crustal magnetic fields, such as auroral electrons precipitation [e.g., Brain et al., 2006a; Dubinin et al., 2008; Soobiah et al., 2013; Xu et al., 2014; Grard et al., 2015] leading to UV emissions [e.g., Bertauxet al., 2005; Leblanc et al., 2008], the inverted-V signatures presumably associated with enhancements of ion outflows [e.g., Lundin et al., 2006a,b], flux rope formations [e.g., Brain et al., 2010; Morgan et al., 2011; Beharrell and Wild, 2012; Soobiah et al., 2014; Hara et al., 2014, 2017b] presumably in consequence of magnetic reconnection [e.g., Eastwood et al., 2008; Halekas et al., 2009; Harada et al., 2015, 2017], energy-time dispersed electron signatures [Harada et al., 2016], and mini-magnetosphere [e.g., Lundin et al., 2011; Brain and Halekas, 2012, and references therein]. Previous study has shown examples of ion precipitation in crustal magnetic field regions during different electron energy flux intensification signatures on $\sim 9 \%$ of Mars Express (MEX) orbits over 18 months of data [Soobiah et al., 2014]. However, the effects of local crustal magnetic field configurations on precipitating ion fluxes onto Mars have not been investigated on the basis of comprehensive plasma and magnetic field observations yet. Previous numerical simulations have (C)2018 American Geophysical Union. All Rights Reserved. 
suggested that the crustal field can increase precipitating $\mathrm{O}^{+}$ion fluxes substantially leading to the enhancement of sputtering by a factor of $\sim 2$ [Li et al., 2011]. Those numerical simulations also predict that the crustal magnetic fields can vary the $\mathrm{O}^{+}$ion precipitation rates within a factor of 2 , meanwhile the variation due to the upstream solar wind conditions is larger than that due to crustal magnetic fields [Wang et al., 2014, 2015]. The main goal for this study is to present observations of the dependence of precipitating ion fluxes on the local crustal magnetic field configurations using larger data sets accumulated by MAVEN than Hara et al. [2017a].

In this study, we adopt two different coordinate systems, including the Mars-centered Solar Orbital (MSO) coordinate, and the Mars-centered Solar Electric field (MSE) coordinate. The MSO coordinate system is defined with $X$ toward the Sun, the $Z$ axis perpendicular to the ecliptic pointing to the northern hemisphere, and the $Y$ axis completing the right-hand system. The MSE coordinate system is defined with the $X$ axis toward the Sun, the $Z$ axis along the upstream solar wind electric field, and the $Y$ axis also completing the right-hand system. Moreover, we set two magnetic field angles in order to easily infer the local magnetic field topology: the magnetic field elevation $\left(\equiv B_{\theta}\right)$ is defined as the angle relative to the local horizontal plane, i.e., $0^{\circ}$ means the magnetic field is oriented purely horizontal to the Martian surface, while $+90^{\circ}\left(-90^{\circ}\right)$ means the magnetic field is oriented radially upward (downward). The magnetic field azimuth (三 $\left.B_{\phi}\right)$ is defined as the angle in the local horizontal plane with $0^{\circ}$ in the local eastward direction and $90^{\circ}$ in the local northward direction. These local magnetic field angles were previously utilized in Brainet al. [2006b].

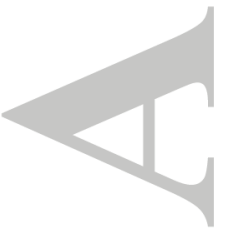

(C)2018 American Geophysical Union. All Rights Reserved. 


\section{MAVEN Observations Example}

In this section, we present an example of ions precipitating into the Martian atmosphere in the vicinity of the strong crustal magnetic field observed by the Solar Wind Ion Analyzer (SWIA) and magnetometer (MAG) experiments onboard MAVEN on 1 November 2015 (Orbit \#2120). SWIA is a cylindrically symmetric electrostatic analyzer with deflection optics, allowing the sampling of high-cadence ion velocity distributions with energies from $\sim 25 \mathrm{eV}$ to $\sim 25 \mathrm{keV}$ as fast as every $4 \mathrm{~s}$ with high-energy resolution (7.5\%) and angular resolution $\left(4.5^{\circ} \times 3.75^{\circ}\right.$ in the sunward direction, $22.5^{\circ} \times 22.5^{\circ}$ elsewhere $)$. The total field of view $(\mathrm{FOV})$ is $360^{\circ} \times 90^{\circ}$ [Halekas et al., 2015b, 2017]. MAG is a tri-axial fluxgate magnetometer to sample vector magnetic fields as fast as $32 \mathrm{~Hz}$ [Connerneyet al., 2015]. Precipitating ion fluxes are calculated by SWIA through integration over any ions detected in the SWIA angular bins whose field of views (FOVs) are within a cone angle of $75^{\circ}$ along the positive radial direction relative to the center of Mars. This methodology is identical to the previous studies [Leblanc et al., 2015; Hara et al., 2017a]. During this event, MAVEN traveled from north to south in the dayside induced magnetosphere and ionosphere. When MAVEN was located at altitudes $\lesssim 500 \mathrm{~km}$, the magnetic field strength $(-\boldsymbol{B}-)$ in Figure 1e was much stronger than $100 \mathrm{nT}$; therefore, MAVEN crossed over a significant strong crustal magnetic field region (see also, Figures 1i). Blue dashed lines in Figures 1e-1g demonstrate that the crustal field model reproduced by Morschhauser et al. [2014] are in good agreement with the MAVEN magnetic field measurements, especially between 12:02 and 12:16 with altitudes lower than $\sim 350 \mathrm{~km}$.

One remarkable feature observed in this period is that SWIA intermittently recorded enhancements of precipitating ion fluxes (of all species as SWIA does not distinguish

(C)2018 American Geophysical Union. All Rights Reserved. 
composition) with energies up to a few keV around e.g., 12:01, 12:12, and 12:14, when the spacecraft was in the altitudes between 200 and $350 \mathrm{~km}$ (between pairs of magenta vertical dashed lines). Figure 1d shows that the total precipitating ion fluxes are enhanced by a factor of $\sim 8$, and $\sim 4$ relative to the average total precipitating ion fluxes during individual inbound and outbound segments (red horizontal dashed lines in Figure 1c). Interestingly, these enhancements are coincident with the amplitude of the magnetic field elevation $\left(\left|B_{\theta}\right|\right)$ reaching at least $\sim 45^{\circ}$ and above in Figure 1f, i.e., the local magnetic field is oriented radial. Smaller enhancements of precipitating ion fluxes associated with the radial local magnetic field are also present in the lower altitude region, such as around 12:04 and 12:09. Figure 1b presents the SWIA FOV coverage, defined as the total solid angles summed over the SWIA angular bins used in calculations for precipitating ions, divided by the solid angle of a cone with apex angle $75^{\circ}$, i.e., $2 \pi\left(1-\cos \left(75^{\circ}\right)\right) \simeq 4.66$ str. Note that the SWIA FOV coverage is entirely larger than $\sim 0.7$, indicating that SWIA is capable of widely detecting ions precipitating into the Martian upper atmosphere.

Pink curves in Figures $1 \mathrm{i}$ and $1 \mathrm{j}$ are traced model crustal field lines in the vicinity of the spacecraft trajectory based on Morschhauser et al. [2014]. These field line tracings were performed until they reached the surface or the empirical induced magnetosphere boundary from Trotignon et al. [2006]. Figures $1 \mathrm{i}$ and $1 \mathrm{j}$ visually show that precipitating ion fluxes tend to be enhanced along the radial crustal field lines, i.e., in the magnetic "cusp" region, while their fluxes are significantly reduced under the closed crustal magnetic field loops due to the magnetic "shielding" effect.

The STATIC experiment adopts a similar toroidal electrostatic analyzer with a $360^{\circ} \times$ $90^{\circ} \mathrm{FOV}$ and is capable identifying ion species through a time-of-flight (TOF) velocity (C)2018 American Geophysical Union. All Rights Reserved. 
analyzing system [McFadden et al., 2015]. STATIC detects ions with energies from $\sim 0.1$ eV up to $\sim 30 \mathrm{keV}$ as fast as also every $4 \mathrm{sec}$ with energy resolution $(\sim 15 \%)$ and angular resolution $\left(22.5^{\circ} \times 6^{\circ}\right)$. STATIC's FOV and energy range are highly variable according to the spacecraft altitude and/or attitude during every orbit. Hence, unfortunately, the FOV of STATIC was not suitable for capturing precipitating ion populations during this orbital crossing because of the spacecraft attitude. Nevertheless, STATIC measurements during enhancements of precipitating ion fluxes indicate that high-mass planetary ion species make up most of the lower energy populations $(\lesssim 100 \mathrm{eV})$ while low-mass ions (i.e., protons) comprise most of the higher energy populations (not shown here). Thus most of which is analyzed in this study is interpreted as planetary heavy ions mainly composed of $\mathrm{O}^{+}$, the dominant species of these altitudes. Note that Soobiah et al. [2018; MAVEN case studies of plasma dynamics in low altitude crustal magnetic field at Mars 1: Dayside ion intensifications associated with radial crustal magnetic field, in preparation to submit to J. Geophys. Res. Space Physics] investigates the detailed plasma dynamics associated with such precipitating ion phenomena in the vicinity of the dayside crustal magnetic fields.

\section{Statistical Results}

As mentioned above, precipitating ion fluxes into the Martian atmosphere are highly variable by at least an order of magnitude depending on the upstream solar wind conditions and/or the observed locations from dayside to nightside [e.g., Hara et al., 2011, 2017a]. Similar to the previous approach [Leblanc et al., 2015; Hara et al., 2017a], we focus on the behaviors of ions precipitating into the Martian ionosphere observed by MAVEN at an altitude between 200 and $350 \mathrm{~km}$, which is approximately close to the Martian exobase

(C)2018 American Geophysical Union. All Rights Reserved. 
[e.g., Yagi et al., 2012]. In order to examine the effects of the local crustal magnetic field topology on the precipitating ion fluxes, we analyzed precipitating ion fluxes integrated over the whole SWIA energy range, which are normalized by the average values between 200 and $350 \mathrm{~km}$ during individual MAVEN orbital inbound/outbound segments, namely, we statistically used the results as shown in Figure 1d. The surveyed time interval is from 1 December 2014 until 28 February 2017; that is approximately more than one Martian year. In this study, we only used the SWIA data, whose FOV coverage is larger than 0.7 (see, Figure 1b), in order to widely capture ion populations precipitating toward the Martian ionosphere in the same way to Hara et al. [2017a].

Figure 2 presents the statistical distributions with respect to the normalized precipitating ion fluxes as a function of the absolute value of the observed local magnetic elevation angle $\left(\left|B_{\theta}\right|\right)$ and the total magnetic strength $(|\boldsymbol{B}|)$. Hence, $\left|B_{\theta}\right|=0^{\circ}$ means that the local magnetic field is oriented to the local horizontal plane, indicating closed field lines, while $\left|B_{\theta}\right|=90^{\circ}$ means that the local magnetic field is oriented radially, indicating potentially opened field lines, likely in the magnetic cusp region. In this study, we simply define the observed region as dayside (nightside) with the solar zenith angle smaller (larger) than $90^{\circ}$. Figure 2 illustrates that some features are similar regardless of the effects due to the dayside (Figure 2a) or nightside (Figure 2b). Under the horizontal (closed) magnetic field configurations $\left(\left|B_{\theta}\right| \lesssim 30^{\circ}\right)$ with a strength stronger than $\sim 50 \mathrm{nT}$ (dayside; Figure 2a) and $\sim 30 \mathrm{nT}$ (nightside; Figure $2 \mathrm{~b}$ ), the normalized precipitating ion fluxes are gradually decreasing from the average precipitation values as the local crustal field strength gets stronger. This is in agreement with previous simulations of the increased deflection of incoming solar wind protons into the Martian ionosphere, under an increasingly strong

(C)2018 American Geophysical Union. All Rights Reserved. 
horizontal induced magnetic field [Shematovich et al., 2011]. In particular, the normalized precipitating ion fluxes reduce by approximately half to the average values when the local field strength exceeds $\sim 100 \mathrm{nT}$. This flux decreasing trend is likely more obvious on the nightside (Figure $2 \mathrm{~b}$ ) rather than on the dayside (Figure 2a). On the other hand, under the radial magnetic field configurations $\left(\left|B_{\theta}\right| \gtrsim 60^{\circ}\right)$, the normalized precipitating ion fluxes are gradually increasing up to by a factor of $2-3$ relative to the average precipitation values, as the local crustal field strength gets stronger. This flux increasing trend is conversely more obvious on the dayside (Figure 2a) rather than on the nightside (Figure 2b). Although there are some data gaps, the normalized precipitating ion fluxes might be slightly increasing by a several tens of $\%$ for magnetic field strength weaker than $\sim 10 \mathrm{nT}$ due to the weak shielding effects, due to larger ion gyro radii being less deflected under low magnetic field strength conditions. It should be noted here that there are a few bins that have a large standard error as shown in Figure S1 in the supporting information; however, Figure S1 obviously shows that the tendencies of the normalized precipitating ion fluxes with respect to the local magnetic field configurations mentioned above are sufficiently valid.

Figure 2c is a difference plot, which is obtained by simply subtracting Figure $2 \mathrm{~b} 1$ from Figure 2a1. It is clearly shown that a lot of bins are colored by gray, indicating that these differences between dayside and nightside are not statistically significant. However, interestingly, the normalized precipitating ion fluxes observed in the dayside tend to be relatively enhanced those observed in the nightside under the local magnetic field above $\sim 10 \mathrm{nT}$, while this trend tend to be opposite under the local magnetic field smaller than

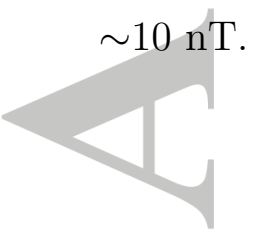

(C)2018 American Geophysical Union. All Rights Reserved. 
Here we also divide Figure 2 according to the observed subsolar longitude (Figure 3) in order to investigate global effects on crustal field locations with respect to the observed local time. As mentioned in section 1, the Martian strongest crustal magnetic fields are primarily distributed on the southern hemisphere with a geographic longitude of $\sim 180^{\circ}$ [e.g., Acua et al., 1998, 1999]; therefore, Figure 3 shows the statistical distributions of the normalized precipitating ion fluxes as a function of the local magnetic field configurations under the strongest crustal magnetic field located on (a) duskside, (b) dayside, (c) dawnside, and (d) nightside, respectively. Regardless of the subsolar longitude, Figure 3 has similar dependences associated with the local magnetic field configurations on precipitating ion fluxes mentioned above. Note that the normalized precipitating ion fluxes are remarkably enhanced under the radial magnetic field configuration with an amplitude stronger than $\sim 100 \mathrm{nT}$, when the strongest crustal magnetic fields are located on the dayside (Figure 3b1). While Figure 2 divides the MAVEN observations into the dayside and nightside, Figure 3 accumulates both dayside and nightside observations to get better data statistics. However, note also that we can still measure similar dependences associated with the local magnetic field configurations on precipitating ion fluxes, even though we again separate Figure 3 into the dayside and nightside.

Figure 4 compares these statistical distributions of precipitating ion fluxes with respect to the local crustal magnetic field configurations between the $+\boldsymbol{E}$ and $-\boldsymbol{E}$ hemispheres. Since Figure 4 only uses MAVEN data when the direct measurements of the upstream solar wind and the Martian ionosphere are available within a single MAVEN orbit, the total number of data points for SWIA measurements in Figures 4a2-4d2 is significantly smaller than those in Figures 2a2-2b2, especially for the dayside because of the MAVEN (C)2018 American Geophysical Union. All Rights Reserved. 
orbital configuration. Moreover, in the same manner as Hara et al. [2017a], an additional data selection criterion is imposed with the standard deviation of the clock angle of the interplanetary magnetic field (IMF) between individual orbital inbound and outbound crossings must be smaller than $45^{\circ}$, in order to precisely transform the SWIA measurements to the MSE coordinates. Figure 4 clearly shows that the global distributions are mostly similar to Figure 2. Although, previous studies have shown that precipitating heavy ion fluxes observed in the $-\boldsymbol{E}$ hemisphere are generally stronger than those observed in the $+\boldsymbol{E}$ hemisphere [e.g., Luhmann and Kozyra, 1991; Chaufray et al., 2007; Fang et al., 2013; Curry et al., 2015; Hara et al., 2017a], we can not measure an obvious difference with respect to the dependence of local magnetic field configurations on the normalized precipitating ion fluxes between $\pm \boldsymbol{E}$ hemispheres. We also made the difference plots shown as Figure 2c for Figures 3 and 4 (not shown here); however, these differences are smaller than these standard errors for many bins. We thus conclude that the local crustal magnetic configurations consistently play a role in controlling ion fluxes precipitating into Mars.

\section{Discussion}

\subsection{Heavy Ions/Protons Dependence}

The previous section focuses on SWIA observations of precipitating ion fluxes observed in the altitude between 200 and $350 \mathrm{~km}$, which is approximately close to the Martian exobase; such that ion species like planetary heavy ions (e.g., $\mathrm{O}^{+}, \mathrm{O}_{2}^{+}$) or solar wind origin protons $\left(\mathrm{H}^{+}\right)$moving towards Mars have a large probability to impact the Martian upper atmosphere. In this section, here we perform comparable analyses by using the STATIC observations.

(C)2018 American Geophysical Union. All Rights Reserved. 
As described in Hara et al. [2017a], there are certain observational constrains when analyzing STATIC data. First, STATIC usually operates in the "Conic" mode with energies between $\sim 0.1$ and $500 \mathrm{eV}$ at altitudes between 200 and $350 \mathrm{~km}$; therefore, the Conic mode cannot capture precipitating pick up ion populations accelerated up to the high-energy range (at least a few $\mathrm{keV}$ and above). So in this study we used the STATIC data only when it operates in the "Protect" mode, allowing detection of ions with energies between $\sim 30 \mathrm{eV}$ and $\sim 30 \mathrm{keV}$. Second, in principle we should use the high-dimensional STATIC (so-called "D0" and "D1") data products including energy $(E)$, angular (deflection $D$, azimuth $A$ ), mass $(M)$ arrays, in order to compute precipitating ion fluxes; however, these higher dimensional STATIC data products are only available every 4-128 s, depending on its energy modes and telemetry rates. This means that the volume of the STATIC data used in this study is significantly smaller than that of the SWIA data. In order to augment the data statistics as much as possible, we employ the STATIC "D4" data product $(4 D \times 16 A \times 2 M)$. While the STATIC D4 data product has no energy $(E)$ information, it is always available under the Protect mode as fast as every $4 \mathrm{~s}$ and it is sufficient to compute at least the energy-integrated precipitating ion fluxes for both heavy ions and protons, allowing us to make analogous distributions to those shown in Figures 2 and 4. Figure 5 uses similar statistical distributions to Figures 2 and 4; however, the STATIC data is derived from the STATIC D4 data product for both heavy ions (1: top) and protons (2: center) during the Protect mode. Figure 5 has some similar tendencies of precipitating ion fluxes with respect to the local magnetic field configurations consistent with those seen in Figure 2, regardless of the ion species. For example, the normalized precipitating ion fluxes gradually decreases where the local magnetic fields are horizontal with the elevation (C)2018 American Geophysical Union. All Rights Reserved. 
angle $\left(\left|B_{\theta}\right|\right)$ smaller than $\sim 30^{\circ}$ as the local field strength $(|\boldsymbol{B}|)$ increases, whereas they are enhanced by a factor of approximately 2-3 under the radial magnetic field fields $\left(\left|B_{\theta}\right|\right.$ $\left.\gtrsim 60^{\circ}\right)$. It should be mentioned here again that we also made the difference plot shown as Figure 2c for Figures 5 (not shown here); however, these differences are also smaller than these standard errors for many bins. Given that the local crustal magnetic field is strong with a strength of $100 \mathrm{nT}$, the gyro radii of the planetary $\mathrm{O}^{+}$ions (solar wind protons) are calculated to be $\sim 58$ (14) $\mathrm{km}$ with energy of $100 \mathrm{eV}$, and $\sim 183$ (46) km with energy of 1 keV. These spatial scales are approximately comparable or sufficiently smaller than those of the Martian crustal fields. It indicates that both ions tend to be magnetized, making both heavy ions and protons motions likely controlled by the field structure. It thus might be a possible explanation of why we could not measure the remarkable differences associated with the local magnetic field configurations between heavy ions and protons precipitating toward the Martian upper atmosphere from the current data sets of the STATIC measurements.

\subsection{Precipitating Ion Energy Spectra}

So far, we have only discussed precipitating ion fluxes integrated over the whole SWIA (or STATIC) energy range. But it is also important to understand the characteristics of the energy spectra with respect to precipitating ion fluxes among a variety of local magnetic field configurations as shown in Figure 6. Indeed, precipitating ion fluxes observed on the dayside are significantly larger than those on the nightside (see, e.g, black solid and dashed lines in Figure 6a). In addition, precipitating ion fluxes observed in the $-\boldsymbol{E}$

hemisphere are also slightly larger than those in the $+\boldsymbol{E}$ hemisphere (see, e.g., black solid and dashed lines in Figures 6e and 6f). It should be noticed that regardless of the observed (C)2018 American Geophysical Union. All Rights Reserved. 
locations including dayside/nightside, and $\pm \boldsymbol{E}$ hemispheres, it is likely that the crustal magnetic fields significantly shield ions, especially with energies lower than a few keV, from precipitating toward the Martian upper atmosphere under strong and horizontal crustal field configurations (seen as the flux decrease at energies $<$ a few $\mathrm{keV}$ in the blue lines). However, under the radial crustal field configurations (red lines), ions in a similar energy range are easily allowed to precipitate toward the Martian upper atmosphere. At energies higher than a few $\mathrm{keV}$, precipitating ion fluxes tend to be approximately comparable

to the average energy spectra (black solid lines). This indicates that crustal magnetic fields play a significant role in controlling precipitating low-energy ions, while high-energy ions are able to penetrate into the Martian upper atmosphere regardless of the crustal magnetic fields. It is because small gyro radii ions are more effectively shielded compared to large gyro radii ions. These high-energy ions have been predicted to be a significant driver for sputtering [e.g., Leblanc and Johnson, 2001, 2002; Wang et al., 2014]. Note that the standard errors for individual energy spectra are negligibly small, because the total number of data points used here are at least greater than 10000 .

\subsection{Magnetic Topologies Deduced from the SWEA Electrons Measurements}

MAVEN is also capable of measuring both suprathermal solar wind electrons and ionospheric photoelectrons in the Martian plasma environment by the Solar Wind Electron Analyzer (SWEA) [Mitchell et al., 2016]. SWEA is a symmetric electrostatic analyzer designed to measure suprathermal electrons energy and angular distributions of $3 \mathrm{eV}$ to $4.6 \mathrm{keV}$ every 2 sec. The instantaneous FOV is $360^{\circ} \times 7^{\circ}$; however, an overall FOV is $360^{\circ} \times 120^{\circ}$ through deflection sweep by $\pm 60^{\circ}$. These SWEA electron measurements are also a powerful tool to deduce local magnetic topologies, because electrons are typically (C)2018 American Geophysical Union. All Rights Reserved. 
magnetized and their guiding center motions are strictly controlled along the direction of the local magnetic field. Interestingly, the SWEA shape parameter (not shown here but explained briefly later) during our example shown in Figure 1 indicates that the local magnetic field is open during the enhancement of precipitating ion fluxes observed in the inbound segment around 12:01. But then, it remains closed for those observed in the outbound segment around 12:12 and 12:14, nevertheless, the local magnetic fields are likely to be radial. Indeed, some MHD models also predict that the radial magnetic field around the Martian exobase is not always open field lines [e.g., Luhmann et al., 2015]. So we classify our statistical SWIA dataset used in Figure 2 into the local magnetic field topologies deduced from the SWEA measurements.

In order to systematically estimate if the observed field lines are open or closed, we employ the shape parameter characterized from the Martian ionospheric photoelectron peaks recorded in the SWEA pitch angle resolved electron energy spectra (see, in detail Xu et al. [2017]). Since the Martian photoelectron signatures are essential to determine the shape parameter, in this study, we divided our statistical SWIA data set in computing precipitating ion fluxes only observed in the dayside by using the SWEA electron shape parameter. A closed field is determined by photoelectrons measured in both parallel and antiparallel directions to the local magnetic field line, resulting in the shape parameter smaller than unity $(<1)$ in both directions. On the other hand, an open field is determined by photoelectrons measured in one direction and solar wind electrons measured in the opposite direction, resulting in the shape parameter smaller than unity $(<1)$ in one direction and larger than unity $(>1)$ in the opposite direction [Xu et al., 2017].

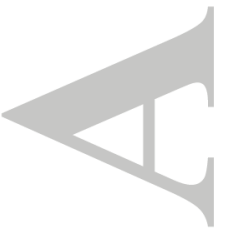

(C)2018 American Geophysical Union. All Rights Reserved. 
As shown in Xu et al. [2017], the SWEA electron shape parameters suggest that the closed field line configuration is the most common in the dayside at altitudes between 200 and $350 \mathrm{~km}$ with an occurrence rate higher than $80 \%$, relative to our statistical data set, while the occurrence rate of open field line configuration is lower than $10 \%$. Figure 7 shows the energy spectra of precipitating ion fluxes observed on the dayside between closed (blue) and open (red) field line configurations deduced by the SWEA electron shape parameter. One interesting feature is that observed precipitating ion fluxes under the open field line configurations (red solid line) are larger than the average spectra (black solid line in Figure 7, which is identical to the black solid line in Figure 6a) for the all energy regime, while those flux enhancements are only seen in precipitating ions with energies lower than a few keV in Figure 6. The total precipitating ion fluxes integrated over the whole SWIA energy range $\left(F_{\text {tot }}\right)$ under the open field line configurations are approximately $68 \%$ larger than those observed in all the dayside regardless of the local magnetic field configurations. On the other hand, the $F_{\text {tot }}$ under the closed field line configurations is slightly smaller by approximately $16 \%$ than the average value.

Even only among the closed field line configurations (blue solid, dotted, dashed lines in Figure 7), ions populations with energies lower than a few $\mathrm{keV}$ are easily precipitating under the radial magnetic field configurations (blue dashed line), while their fluxes are significantly reduced under the horizontal magnetic field configurations with a strength larger than $100 \mathrm{nT}$ (blue dotted line). Compared with the average precipitating ion fluxes integrated over the SWIA energy range observed in the dayside, the $F_{\text {tot }}$ under the radial closed field line configurations (blue dashed line) is larger by $\sim 38 \%$, while the $F_{\text {tot }}$ under the horizontal closed field line configurations with a strength larger than $100 \mathrm{nT}$ (blue (C)2018 American Geophysical Union. All Rights Reserved. 
dotted line) is smaller by $\sim 49 \%$. Therefore, we are still able to measure the tendencies as seen in Figure 6 from the closed field line configurations deduced from the SWEA shape parameter. The possible interpretation to understand these tendencies is that the loop tops of the radial closed field lines can be located at higher altitude and have a field strength significantly weaker than those of the horizontal closed field lines located at lower altitude. It allows ion populations to easily penetrate toward the Martian upper atmosphere, leading to the enhancement of precipitating ion fluxes even under the closed radial field line configurations.

\section{Concluding Remarks}

In this paper, we have statistically investigated the influence of local crustal magnetic field configurations on precipitating ion fluxes into the upper atmosphere of Mars based on the MAVEN observations from 1 December 2014 through 28 February 2017. As statistically demonstrated by Hara et al. [2017a], precipitating ion fluxes into the Martian upper atmosphere can vary by at least an order of magnitude depending on the upstream solar wind conditions, $\pm \boldsymbol{E}$ hemispheres, and dayside/nightside hemispheres. An enhancement of this factor is significant enough to hide the effects of the local magnetic field configurations on precipitating ion fluxes toward the Martian upper atmosphere. In order to extract this effect associated with the local magnetic field configurations, we computed the precipitating ion fluxes from every SWIA (or STATIC) three-dimensional distribution functions recorded in the altitudes between 200 and $350 \mathrm{~km}$, and normalized their fluxes by the averaged values observed in these altitude ranges for individual MAVEN orbital inbound/outbound segments (see Figures 1c and 1d). Here are summarized the main conclusions discussed in this paper (see also Figure 8):

(C)2018 American Geophysical Union. All Rights Reserved. 
1. The precipitating ion fluxes integrated over the whole SWIA energy range are typically enhanced by a factor of $2-3$ under radial magnetic field configuration $\left(-B_{\theta}-\gtrsim\right.$ $\left.60^{\circ}\right)$ as clearly presented in Figure 2.

2. The precipitating ion fluxes are significantly reduced by approximately a factor of two under the horizontal (closed) magnetic field configurations $\left(\left|B_{\theta}\right| \lesssim 30^{\circ}\right)$ with strength larger than approximately $100 \mathrm{nT}$ due to the magnetic shielding effect.

3. The influence of the local magnetic field configuration on the precipitating ion fluxes are consistently seen regardless of the observed locations (i.e., dayside/nightside; Figure 2 ), the subsolar longitude (Figure 3), and the $\pm \boldsymbol{E}$ hemispheres in the MSE coordinates as indicated by Figure 4 .

4. We also measured the influence of the local magnetic field configuration on the precipitating ion fluxes for both heavy ions and protons; however, significant differences between ion species could not be found from the current MAVEN/STATIC data sets as shown in Figure 5.

5. Figure 6 indicates that precipitating ions with energies lower than a few $\mathrm{keV}$ are especially controlled by the local magnetic field configuration, while precipitating highenergy ion fluxes are likely independent of the local magnetic field configuration.

6. According to the magnetic topologies deduced from the SWEA shape parameter, we could identify the influence of the local magnetic field configuration on the precipitating ion fluxes also for closed field line configurations (see Figure 7). It implies that the loop tops of the radial closed field lines can be found at significantly high altitude for ions to penetrate toward the Martian upper atmosphere, resulting in the enhancements of precipitating ion fluxes even under the radial closed field configurations.

(C)2018 American Geophysical Union. All Rights Reserved. 
As mentioned above, precipitating ion fluxes can vary with the local magnetic field configurations by a factor of 2-3. This variation scale due to the local magnetic field configurations is thus typically comparable to the numerical predictions [Li et al., 2011; Wang et al., 2014, 2015]; however, the influence of the crustal fields is still smaller than other factors, such as the upstream solar wind conditions, $\pm \boldsymbol{E}$, and dayside/nightside hemispheres, because they can be varied by at least an order of magnitude [Hara et al.,

2017a]. Therefore, our results suggest that the local crustal field configurations can be regarded as a secondary and unique contributor in controlling the precipitating ion fluxes into the Martian upper atmosphere.

Acknowledgments. The authors wish to acknowledge valuable supports from the science team members of the MAVEN mission. This study presented in this paper was funded by the NASA MAVEN project. The MAVEN data used in this paper are publicly available in NASA's Planetary Data System (https://pds-ppi.igpp.ucla.edu).

\section{References}

Acuña, M. H., J. E. P. Connerney, P. Wasilewski, R. P. Lin, K. A. Anderson, C. W. Carlson, J. McFadden, D. W. Curtis, D. Mitchell, H. Reme, C. Mazelle, J. A. Sauvaud, C. D’Uston, A. Cros, J. L. Medale, S. J. Bauer, P. Cloutier, M. Mayhew, D. Winterhalter, and N. F. Ness (1998), Magnetic field and plasma observations at Mars: Initial results of the Mars Global Surveyor mission, Science, 279, 1676-1680, doi: 10.1126/science.279.5357.1676.

Acuña, M. H., J. E. P. Connerney, N. F. Ness, R. P. Lin, D. Mitchell, C. W. Carlson, J. McFadden, K. A. Anderson, H. Reme, C. Mazelle, D. Vignes, P. Wasilewski, and (C)2018 American Geophysical Union. All Rights Reserved. 
P. Cloutier (1999), Global Distribution of Crustal Magnetization Discovered by the Mars Global Surveyor MAG/ER Experiment, Science, 284, 790-793, doi:10.1126/science.284. 5415.790.

Beharrell, M. J., and J. A. Wild (2012), Stationary flux ropes at the southern terminator of Mars, J. Geophys. Res., 117, A12212, doi:10.1029/2012JA017738.

Bertaux, J.-L., F. Leblanc, O. Witasse, E. Quemerais, J. Lilensten, S. A. Stern, B. Sandel, and O. Korablev (2005), Discovery of an aurora on Mars, Nature, 435, 790-794, doi: 10.1038/nature03603.

Brain, D., and J. S. Halekas (2012), Aurora in Martian Mini Magnetospheres, in Auroral Phenomenology and Magnetospheric Processes: Earth and Other Planets, AGU Geophys. Monogr. Ser., vol. 197, edited by A. Keiling, E. Donovan, and T. Karlsson, pp. 123-132, doi:10.1029/2011GM001201.

Brain, D. A., J. S. Halekas, L. M. Peticolas, R. P. Lin, J. G. Luhmann, D. L. Mitchell, G. T. Delory, S. W. Bougher, M. H. Acuña, and H. Rème (2006a), On the origin of aurorae on Mars, Geophys. Res. Lett., 33, L01201, doi:10.1029/2005GL024782.

Brain, D. A., D. L. Mitchell, and J. S. Halekas (2006b), The magnetic field draping direction at Mars from April 1999 through August 2004, Icarus, 182, 464-473, doi: 10.1016/j.icarus.2005.09.023.

Brain, D. A., A. H. Baker, J. Briggs, J. P. Eastwood, J. S. Halekas, and T.-D. Phan (2010), Episodic detachment of Martian crustal magnetic fields leading to bulk atmospheric plasma escape, Geophys. Res. Lett., 37, L14108, doi:10.1029/2010GL043916.

Brain, D. A., J. P. McFadden, J. S. Halekas, J. E. P. Connerney, S. W. Bougher, S. Curry, C. F. Dong, Y. Dong, F. Eparvier, X. Fang, K. Fortier, T. Hara, Y. Harada, B. M. (C)2018 American Geophysical Union. All Rights Reserved. 
Jakosky, R. J. Lillis, R. Livi, J. G. Luhmann, Y. Ma, R. Modolo, and K. Seki (2015), The spatial distribution of planetary ion fluxes near Mars observed by MAVEN, Geophys.

Res. Lett., 42, 9142-9148, doi:10.1002/2015GL065293.

Chaufray, J. Y., R. Modolo, F. Leblanc, G. Chanteur, R. E. Johnson, and J. G. Luhmann (2007), Mars solar wind interaction: Formation of the Martian corona and atmospheric loss to space, J. Geophys. Res., 112(E11), E09009, doi:10.1029/2007JE002915.

Connerney, J. E. P., J. Espley, P. Lawton, S. Murphy, J. Odom, R. Oliversen, and D. Sheppard (2015), The MAVEN Magnetic Field Investigation, Space Sci. Rev., 195, 257-291, doi:10.1007/s11214-015-0169-4.

Curry, S. M., M. Liemohn, X. Fang, Y. Ma, and J. Espley (2013), The influence of production mechanisms on pick-up ion loss at Mars, J. Geophys. Res. Space Physics, 118, 554-569, doi:10.1029/2012JA017665.

Curry, S. M., J. Luhmann, Y. Ma, M. Liemohn, C. Dong, and T. Hara (2015), Comparative pick-up ion distributions at Mars and Venus: Consequences for atmospheric deposition and escape, Planet. Space Sci., 115, 35-47, doi:10.1016/j.pss.2015.03.026.

Diéval, C., E. Kallio, S. Barabash, G. Stenberg, H. Nilsson, Y. Futaana, M. Holmström, A. Fedorov, R. A. Frahm, R. Jarvinen, and D. A. Brain (2012), A case study of proton precipitation at Mars: Mars Express observations and hybrid simulations, J. Geophys. Res., 117, A06222, doi:10.1029/2012JA017537.

Diéval, C., G. Stenberg, H. Nilsson, and S. Barabash (2013), A statistical study of proton precipitation onto the Martian upper atmosphere: Mars Express observations, J. Geophys. Res. Space Physics, 118, 1972-1983, doi:10.1002/jgra.50229.

Dubinin, E. M., M. Fränz, J. Woch, E. Roussos, J. D. Winningham, R. A. Frahm,

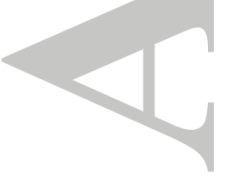
(C)2018 American Geophysical Union. All Rights Reserved. 
A. Coates, F. Leblanc, R. Lundin, and S. Barabash (2008), Access of solar wind electrons into the Martian magnetosphere, Ann. Geophys., 26, 3511-3524, doi:10.5194/ angeo-26-3511-2008.

Eastwood, J. P., D. A. Brain, J. S. Halekas, J. F. Drake, T. D. Phan, M. Øieroset, D. L. Mitchell, R. P. Lin, and M. Acuña (2008), Evidence for collisionless magnetic reconnection at Mars, Geophys. Res. Lett., 35, L02106, doi:10.1029/2007GL032289.

Fang, X., S. W. Bougher, R. E. Johnson, J. G. Luhmann, Y. Ma, Y.-C. Wang, and M. W. Liemohn (2013), The importance of pickup oxygen ion precipitation to the Mars upper atmosphere under extreme solar wind conditions, Geophys. Res. Lett., 40, 1922-1927, doi:10.1002/grl.50415.

Gérard, J.-C., L. Soret, L. Libert, R. Lundin, A. Stiepen, A. Radioti, and J.-L. Bertaux (2015), Concurrent observations of ultraviolet aurora and energetic electron precipitation with Mars Express, J. Geophys. Res. Space Physics, 120, 6749-6765, doi: 10.1002/2015JA021150.

Halekas, J. S. (2017), Seasonal variability of the hydrogen exosphere of Mars, J. Geophys. Res. Planets, 122(5), 901-911, doi:10.1002/2017JE005306.

Halekas, J. S., J. P. Eastwood, D. A. Brain, T. D. Phan, M. Øieroset, and R. P. Lin (2009), In situ observations of reconnection Hall magnetic fields at Mars: Evidence for ion diffusion region encounters, J. Geophys. Res., 114, A11204, doi:10.1029/2009JA014544.

Halekas, J. S., R. J. Lillis, D. L. Mitchell, T. E. Cravens, C. Mazelle, J. E. P. Connerney, J. R. Espley, P. R. Mahaffy, M. Benna, B. M. Jakosky, J. G. Luhmann, J. P. McFadden, D. E. Larson, Y. Harada, and S. Ruhunusiri (2015a), MAVEN observations of solar wind hydrogen deposition in the atmosphere of Mars, Geophys. Res. Lett., 42, 8901-8909, doi: (C)2018 American Geophysical Union. All Rights Reserved. 
10.1002/2015GL064693.

Halekas, J. S., E. R. Taylor, G. Dalton, G. Johnson, D. W. Curtis, J. P. McFadden, D. L. Mitchell, R. P. Lin, and B. M. Jakosky (2015b), The Solar Wind Ion Analyzer for MAVEN, Space Sci. Rev., 195, 125-151, doi:10.1007/s11214-013-0029-z.

Halekas, J. S., S. Ruhunusiri, Y. Harada, G. Collinson, D. L. Mitchell, C. Mazelle, J. P. McFadden, J. E. P. Connerney, J. R. Espley, F. Eparvier, J. G. Luhmann, and B. M. Jakosky (2017), Structure, dynamics, and seasonal variability of the Mars-solar wind interaction: MAVEN Solar Wind Ion Analyzer in-flight performance and science results, J. Geophys. Res. Space Physics, 122, 547-578, doi:10.1002/2016JA023167.

Hara, T., K. Seki, Y. Futaana, M. Yamauchi, M. Yagi, Y. Matsumoto, M. Tokumaru, A. Fedorov, and S. Barabash (2011), Heavy-ion flux enhancement in the vicinity of the Martian ionosphere during CIR passage: Mars Express ASPERA-3 observations, J. Geophys. Res., 116, A02309, doi:10.1029/2010JA015778.

Hara, T., K. Seki, H. Hasegawa, D. A. Brain, K. Matsunaga, and M. H. Saito (2014), The spatial structure of Martian magnetic flux ropes recovered by the Grad-Shafranov reconstruction technique, J. Geophys. Res. Space Physics, 119, 1262-1271, doi:10.1002/ 2013JA019414.

Hara, T., J. G. Luhmann, F. Leblanc, S. M. Curry, K. Seki, D. A. Brain, J. S. Halekas, Y. Harada, J. P. McFadden, R. Livi, G. A. DiBraccio, J. E. P. Connerney, and B. M. Jakosky (2017a), MAVEN observations on a hemispheric asymmetry of precipitating ions toward the Martian upper atmosphere according to the upstream solar wind electric field, J. Geophys. Res. Space Physics, 122, 1083-1101, doi:10.1002/2016JA023348.

Hara, T., D. A. Brain, D. L. Mitchell, J. G. Luhmann, K. Seki, H. Hasegawa, J. P. (C)2018 American Geophysical Union. All Rights Reserved. 
McFadden, J. S. Halekas, J. R. Espley, Y. Harada, R. Livi, G. A. DiBraccio, J. E. P. Connerney, C. Mazelle, L. Andersson, and B. M. Jakosky (2017b), MAVEN observations of a giant ionospheric flux rope near Mars resulting from interaction between the crustal and interplanetary draped magnetic fields, J. Geophys. Res. Space Physics, 122, 828842, doi:10.1002/2016JA023347.

Harada, Y., J. S. Halekas, J. P. McFadden, D. L. Mitchell, C. Mazelle, J. E. P. Connerney, J. R. Espley, D. E. Larson, D. A. Brain, L. Andersson, G. A. DiBraccio, G. Collinson, R. Livi, T. Hara, S. Ruhunusiri, and B. M. Jakosky (2015), Magnetic reconnection in the near-Mars magnetotail: MAVEN observations, Geophys. Res. Lett., 42, 8838-8845, doi:10.1002/2015GL065004.

Harada, Y., D. L. Mitchell, J. S. Halekas, J. P. McFadden, C. Mazelle, J. E. P. Connerney, J. Espley, D. A. Brain, D. E. Larson, R. J. Lillis, T. Hara, R. Livi, G. A. DiBraccio, S. Ruhunusiri, and B. M. Jakosky (2016), MAVEN observations of energy-time dispersed electron signatures in Martian crustal magnetic fields, Geophys. Res. Lett., 43, 939-944, doi:10.1002/2015GL067040.

Harada, Y., J. S. Halekas, J. P. McFadden, J. Espley, G. A. DiBraccio, D. L. Mitchell, C. Mazelle, D. A. Brain, L. Andersson, Y. J. Ma, D. E. Larson, S. Xu, T. Hara, S. Ruhunusiri, R. Livi, and B. M. Jakosky (2017), Survey of magnetic reconnection signatures in the Martian magnetotail with MAVEN, J. Geophys. Res. Space Physics, 122, 5114-5131, doi:10.1002/2017JA023952.

Leblanc, F., and R. E. Johnson (2001), Sputtering of the Martian atmosphere by solar wind pick-up ions, Planet. Space Sci., 49, 645-656, doi:10.1016/S0032-0633(01)00003-4.

Leblanc, F., and R. E. Johnson (2002), Role of molecular species in pickup ion sputtering (C)2018 American Geophysical Union. All Rights Reserved. 
of the Martian atmosphere, J. Geophys. Res., 10(E2), doi:10.1029/2000JE001473.

Leblanc, F., O. Witasse, J. Lilensten, R. A. Frahm, A. Safaenili, D. A. Brain, J. Mouginot, H. Nilsson, Y. Futaana, J. Halekas, M. Holmström, J. L. Bertaux, J. D. Winningham, W. Kofman, and R. Lundin (2008), Observations of aurorae by SPICAM ultraviolet spectrograph on board Mars Express: Simultaneous ASPERA-3 and MARSIS measurements, J. Geophys. Res., 113, A08311, doi:10.1029/2008JA013033.

Leblanc, F., R. Modolo, S. Curry, J. Luhmann, R. Lillis, J. Y. Chaufray, T. Hara, J. McFadden, J. Halekas, F. Eparvier, D. Larson, J. Connerney, and B. Jakosky (2015), Mars heavy ion precipitating flux as measured by Mars Atmosphere and Volatile EvolutioN, Geophys. Res. Lett., 42, 9135-9141, doi:10.1002/2015GL066170.

Li, L., Y. Zhang, Y. Feng, X. Fang, and Y. Ma (2011), Oxygen ion precipitation in the Martian atmosphere and its relation with the crustal magnetic fields, J. Geophys. Res., 116(A15), A08204, doi:10.1029/2010JA016249.

Luhmann, J. G., and J. U. Kozyra (1991), Dayside pickup oxygen ion precipitation at Venus and Mars - Spatial distributions, energy deposition and consequences, J. Geophys. Res., $96(\mathrm{~A} 4)$, 5457-5467, doi:10.1029/90JA01753.

Luhmann, J. G., R. E. Johnson, and M. H. G. Zhang (1992), Evolutionary impact of sputtering of the Martian atmosphere by $\mathrm{O}^{+}$pickup ions, Geophys. Res. Lett., $19(21)$, 2151-2154, doi:10.1029/92GL02485.

Luhmann, J. G., Y.-J. Ma, D. A. Brain, D. Ulusen, R. J. Lillis, J. S. Halekas, and J. R. Espley (2015), Solar wind interaction effects on the magnetic fields around Mars: Consequences for interplanetary and crustal field measurements, Planet. Space Sci., 117, 15-23, doi:10.1016/j.pss.2015.05.004.

(C)2018 American Geophysical Union. All Rights Reserved. 
Lundin, R., D. Winningham, S. Barabash, R. Frahm, M. Holmström, J.-A. Sauvaud, A. Fedorov, K. Asamura, A. J. Coates, Y. Soobiah, K. C. Hsieh, M. Grande, H. Koskinen, E. Kallio, J. Kozyra, J. Woch, M. Fraenz, D. Brain, J. Luhmann, S. McKennaLawler, R. S. Orsini, P. Brandt, and P. Wurz (2006a), Plasma Acceleration Above Martian Magnetic Anomalies, Science, 311, 980-983, doi:10.1126/science.1122071.

Lundin, R., D. Winningham, S. Barabash, R. Frahm, D. Brain, H. Nilsson, M. Holmström, M. Yamauchi, J. R. Sharber, J.-A. Sauvaud, A. Fedorov, K. Asamura, H. Hayakawa, A. J. Coates, Y. Soobiah, C. Curtis, K. C. Hsieh, M. Grande, H. Koskinen, E. Kallio, J. Kozyra, J. Woch, M. Fraenz, J. Luhmann, S. McKenna-Lawler, S. Orsini, P. Brandt, and P. Wurz (2006b), Auroral Plasma Acceleration Above Martian Magnetic Anomalies, Space Sci. Rev., 126, 333-354, doi:10.1007/s11214-006-9086-x.

Lundin, R., S. Barabash, M. Yamauchi, H. Nilsson, and D. Brain (2011), On the relation between plasma escape and the Martian crustal magnetic field, Geophys. Res. Lett., 38, L02102, doi:10.1029/2010GL046019.

Masunaga, K., K. Seki, D. A. Brain, X. Fang, Y. Dong, B. M. Jakosky, J. P. McFadden, J. S. Halekas, J. E. P. Connerney, D. L. Mitchell, and F. G. Eparvier (2017), Statistical analysis of the reflection of incident $\mathrm{O}^{+}$pickup ions at Mars: MAVEN observations, $J$. Geophys. Res. Space Physics, 122, 4089-4101, doi:10.1002/2016JA023516.

McFadden, J. P., O. Kortmann, D. Curtis, G. Dalton, G. Johnson, R. Abiad, R. Sterling, K. Hatch, P. Berg, C. Tiu, D. Gordon, S. Heavner, M. Robinson, M. Marckwordt, R. Lin, and B. Jakosky (2015), MAVEN SupraThermal and Thermal Ion Compostion (STATIC) Instrument, Space Sci. Rev., 195, 199-256, doi:10.1007/s11214-015-0175-6.

Mitchell, D. L., C. Mazelle, J.-A. Sauvaud, J.-J. Thocaven, J. Rouzaud, A. Fedorov, (C)2018 American Geophysical Union. All Rights Reserved. 
P. Rouger, D. Toublanc, E. Taylor, D. Gordon, M. Robinson, S. Heavner, P. Turin, M. Diaz-Aguado, D. W. Curtis, R. P. Lin, and B. M. Jakosky (2016), The MAVEN Solar Wind Electron Analyzer, Space Sci. Rev., 200, 495-528, doi:10.1007/s11214-015-0232-1. Morgan, D. D., D. A. Gurnett, F. Akalin, D. A. Brain, J. S. Leisner, F. Duru, R. A. Frahm, and J. D. Winningham (2011), Dual-spacecraft observation of large-scale magnetic flux ropes in the Martian ionosphere, J. Geophys. Res., 116(A15), A02319, doi:10.1029/ 2010JA016134.

Morschhauser, A., V. Lesur, and M. Grott (2014), A spherical harmonic model of the lithospheric magnetic field of Mars, J. Geophys. Res. Planets, 119, 1162-1188, doi: 10.1002/2013JE004555.

Shematovich, V. I., D. V. Bisikalo, C. Diéval, S. Barabash, G. Stenberg, H. Nilsson, Y. Futaana, M. Holmstrom, and J.-C. Gérard (2011), Proton and hydrogen atom transport in the Martian upper atmosphere with an induced magnetic field, J. Geophys. Res., 116, A11,320, doi:10.1029/2011JA017007.

Shizgal, B. D., and G. G. Arkos (1996), Nonthermal escape of the atmospheres of Venus, Earth, and Mars, Rev. Geophys., 34, 483-505, doi:10.1029/96RG02213.

Soobiah, Y. I. J., S. Barabash, H. Nilsson, G. Stenberg, R. Lundin, A. J. Coates, J. D. Winningham, and R. A. Frahm (2013), Energy distribution asymmetry of electron precipitation signatures at Mars, Planet. Space Sci., 76, 10-27, doi:10.1016/j.pss.2012.10.014.

Soobiah, Y. I. J., J. A. Wild, M. J. Beharrell, S. Barabash, R. J. Lillis, D. L. Mitchell, A. J. Coates, J. D. Winningham, and R. A. Frahm (2014), Properties of a large-scale flux rope and current sheet region on the dayside of Mars: MGS MAG/ER and MEX ASPERA-3 ELS observations, Icarus, 242, 297-315, doi:10.1016/j.icarus.2014.08.019.

(C)2018 American Geophysical Union. All Rights Reserved. 
Trotignon, J. G., C. Mazelle, C. Bertucci, and M. H. Acuña (2006), Martian shock and magnetic pile-up boundary positions and shapes determined from the Phobos 2 and Mars Global Surveyor data sets, Planet. Space Sci., 54, 357-369, doi:10.1016/j.pss. 2006.01 .003 .

Wang, Y.-C., J. G. Luhmann, F. Leblanc, X. Fang, R. E. Johnson, Y. Ma, W.-H. Ip, and L. Li (2014), Modeling of the $\mathrm{O}^{+}$pickup ion sputtering efficiency dependence on solar wind conditions for the Martian atmosphere, J. Geophys. Res. Planets, 119, 93-108, doi:10.1002/2013JE004413.

Wang, Y.-C., J. G. Luhmann, X. Fang, F. Leblanc, R. E. Johnson, Y. Ma, and W.-H. Ip (2015), Statistical studies on Mars atmospheric sputtering by precipitating pickup $\mathrm{O}^{+}$: Preparation for the MAVEN mission, J. Geophys. Res. Planets, 120, 34-50, doi: 10.1002/2014JE004660.

Xu, S., M. W. Liemohn, and D. L. Mitchell (2014), Solar wind electron precipitation into the dayside Martian upper atmosphere through the cusps of strong crustal fields, $J$. Geophys. Res. Space Physics, 119, 10,100-10,115, doi:10.1002/2014JA020363.

Xu, S., D. Mitchell, M. Liemohn, X. Fang, Y. Ma, J. Luhmann, D. Brain, M. Steckiewicz, C. Mazelle, J. Connerney, and B. Jakosky (2017), Martian low-altitude magnetic topology deduced from MAVEN/SWEA observations, J. Geophys. Res. Space Physics, 122, 1831-1852, doi:10.1002/2016JA023467.

Yagi, M., F. Leblanc, J. Y. Chaufray, F. Gonzalez-Galindo, S. Hess, and R. Modolo (2012), Mars exospheric thermal and non-thermal components: Seasonal and local variations, Icarus, 221, 682-693, doi:10.1016/j.icarus.2012.07.022.

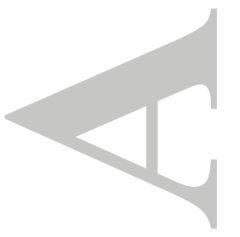

(C)2018 American Geophysical Union. All Rights Reserved. 

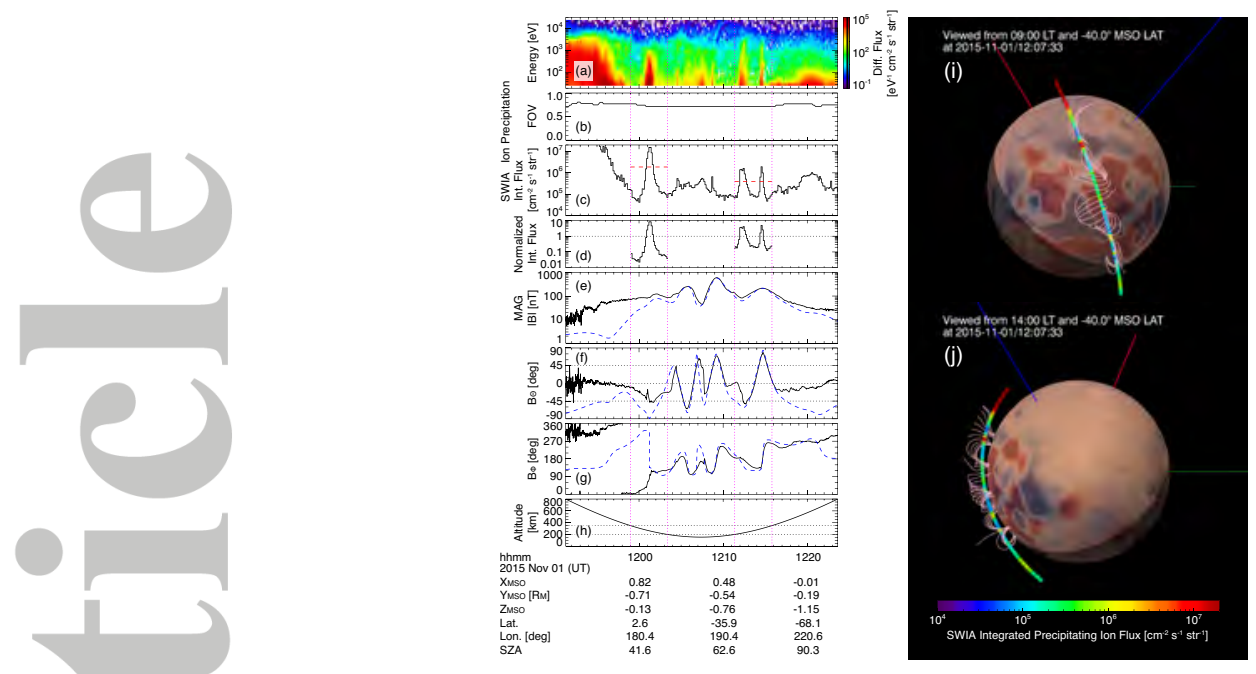

Figure 1. Overview of MAVEN measurements at altitudes lower than $800 \mathrm{~km}$ on 1 November 2015 (Orbit \#2120): Figures 1a-1d show the SWIA measurements of (a) the precipitating ion energy spectra in units of differential number flux ("Diff. Flux"), (b) the field of view (FOV) coverage, (c) the total precipitating ion fluxes ("Int. Flux") integrated over the whole SWIA energy range. The horizontal red dashed lines are the averaged precipitating ion flux levels when the spacecraft located at an altitude between 200 and $350 \mathrm{~km}$ for both inbound and outbound segments. Figure $1 \mathrm{~d}$ is the normalized precipitating ion fluxes, which are derived from the black curve divided by the horizontal red dashed lines in Figure 1c. Figures 1e-1g show the MAG measurements of the local magnetic field (e) strength, (f) elevation and (g) azimuth angles. The blue dashed curves are the modeled crustal fields predicted at MAVEN position by Morschhauser et al. [2014]. Figure $1 \mathrm{~h}$ displays the spacecraft altitude. Figures $1 \mathrm{i}$ and $1 \mathrm{j}$ illustrate the threedimensional orbital trajectory viewed from the local time (LT) of 09:00 (i) and 14:00 (j) with the MSO latitude of $-40^{\circ}$. The background blue-red contour is the radial component of the crustal field model ranging from $-20 \mathrm{nT}$ to $+20 \mathrm{nT}$ at $400 \mathrm{~km}$ [Morschhauser et al., 2014], projected onto the globe surface. Blue, green, and red solid lines are the projected $X_{\mathrm{MSO}}, Y_{\mathrm{MSO}}$, and $Z_{\text {MSO }}$ axes, respectively. The orbital trajectory is color-coded according to the SWIA integrated precipitating ion fluxes, which is same to y-axis range in Figure 1c.

(C)2018 American Geophysical Union. All Rights Reserved. 

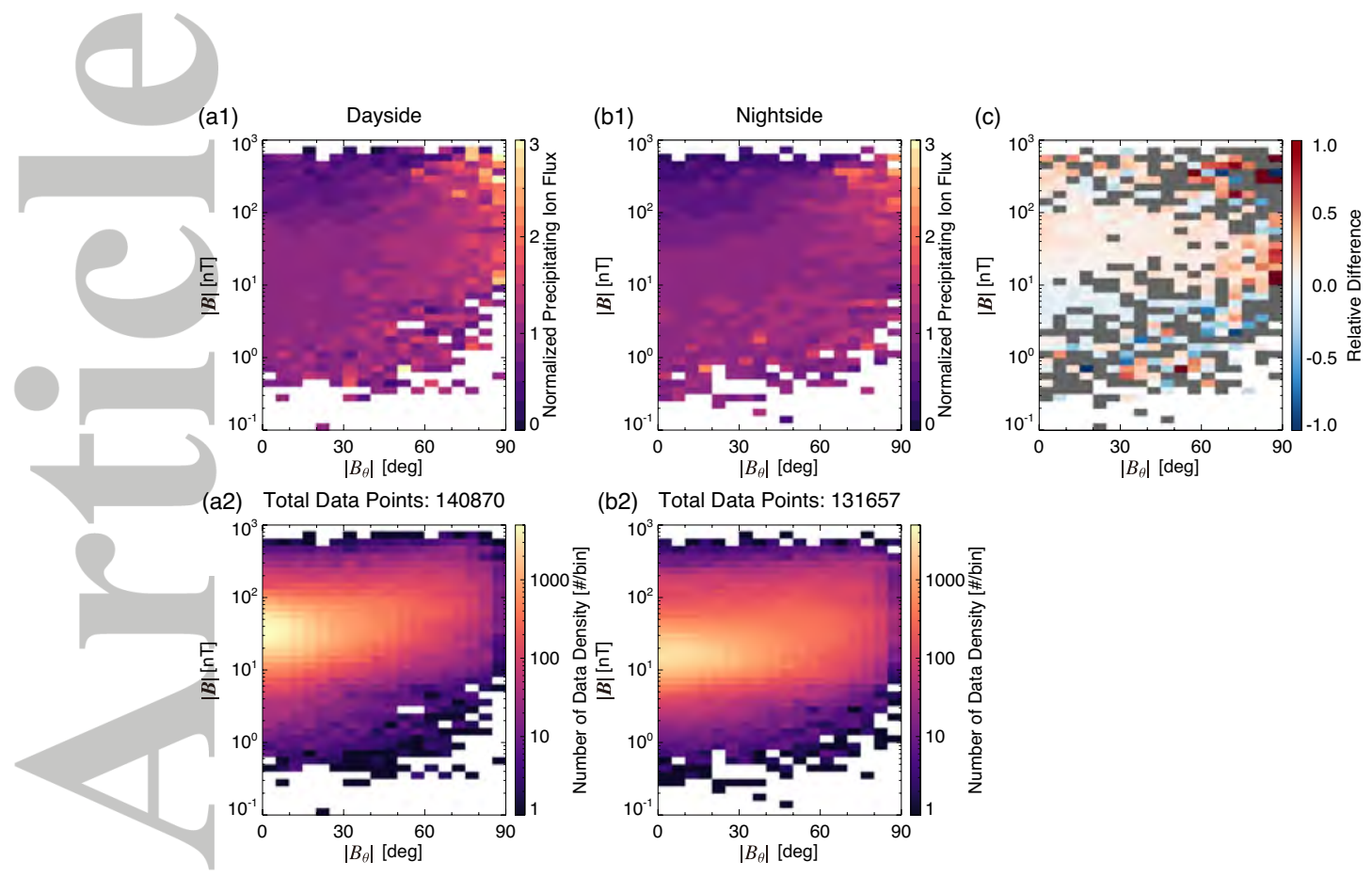

(b2) Total Data Points: 131657

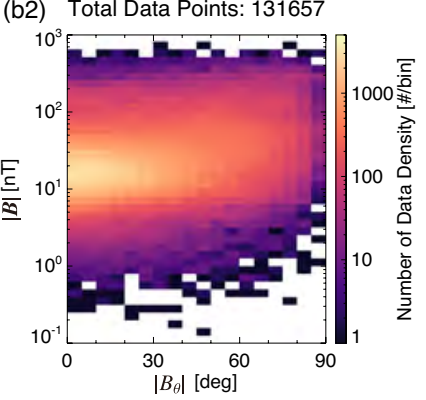

Figure 2. Statistical distributions of (1) the normalized precipitating ion fluxes integrated over the whole SWIA energy range and (2) the total SWIA data, as a function of the absolute value of the local magnetic elevation angle $\left(\left|B_{\theta}\right|\right)$ and the total magnetic field strength $(|\boldsymbol{B}|)$ observed by MAG on (a) dayside and (b) nightside. The individual observed precipitating ion fluxes are normalized by the averaged values with altitudes between 200 and $350 \mathrm{~km}$ for individual orbital inbound and outbound segments. Statistical distributions of the standard error of Figure 2 are shown in Figure S1 in the supporting information. Figure 2c is a difference plot, which is obtained by subtracting Figure 2b1 from Figure 2a1. The gray colored bins indicate that no data is available for either Figure 2a1 or Figure 2b1, or these differences are smaller than the standard error shown in Figure S1.

(C)2018 American Geophysical Union. All Rights Reserved. 

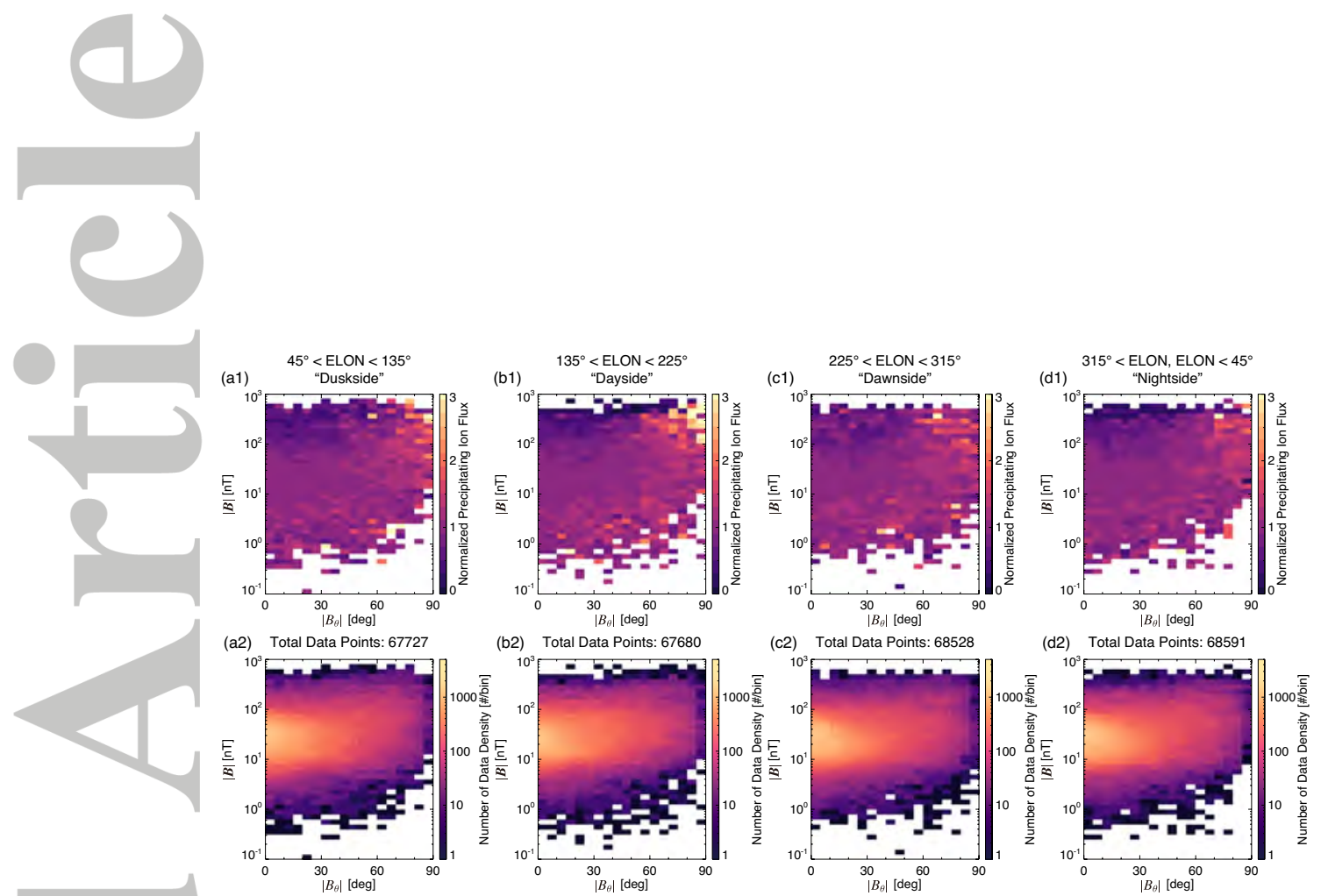

Figure 3. Statistical distributions of (1) the normalized precipitating ion fluxes integrated over the whole SWIA energy range and (2) the total SWIA data, as a function of the absolute value of the local magnetic elevation angle $\left(\left|B_{\theta}\right|\right)$ and the total magnetic field strength $(|\boldsymbol{B}|)$ under the subsolar east longitude $(\mathrm{ELON})$ of (a) $45^{\circ}<\mathrm{ELON}<135^{\circ}$, (b) $135^{\circ}<\mathrm{ELON}<225^{\circ}$, (c) $225^{\circ}$ $<$ ELON $<315^{\circ}$, and (d) $315^{\circ}<$ ELON, ELON $<45^{\circ}$, respectively. Statistical distributions of the standard error of Figure 3 are shown in Figure S2 in the supporting information.

(C)2018 American Geophysical Union. All Rights Reserved. 

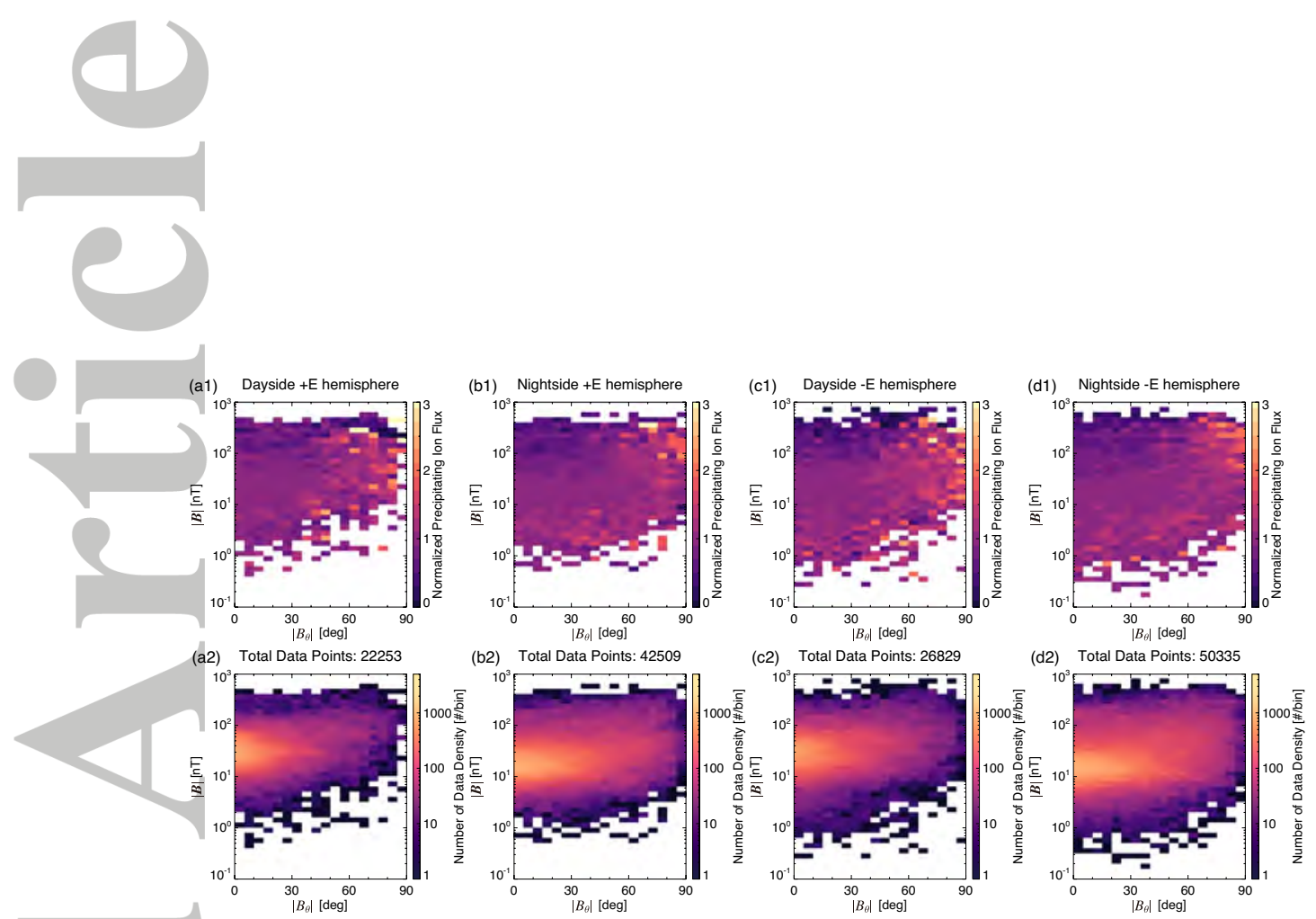

Figure 4. Statistical distributions of (1) the normalized precipitating ion fluxes integrated over the whole SWIA energy range and (2) the total SWIA data, as a function of the absolute value of the local magnetic elevation angle $\left(\left|B_{\theta}\right|\right)$ and the total magnetic field strength $(|\boldsymbol{B}|)$ observed on (a) dayside $+\boldsymbol{E}$, (b) nightside $+\boldsymbol{E}$, (c) dayside $-\boldsymbol{E}$, and (b) nightside $-\boldsymbol{E}$ hemisphere, respectively. Statistical distributions of the standard error of Figure 4 are shown in Figure S3 in the supporting information.

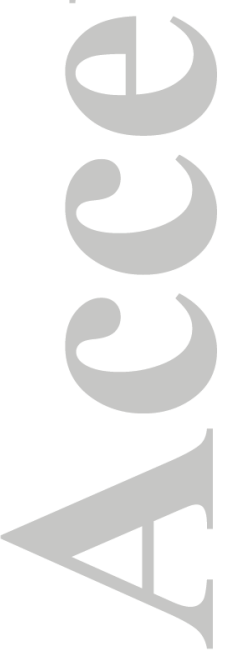

(C)2018 American Geophysical Union. All Rights Reserved. 

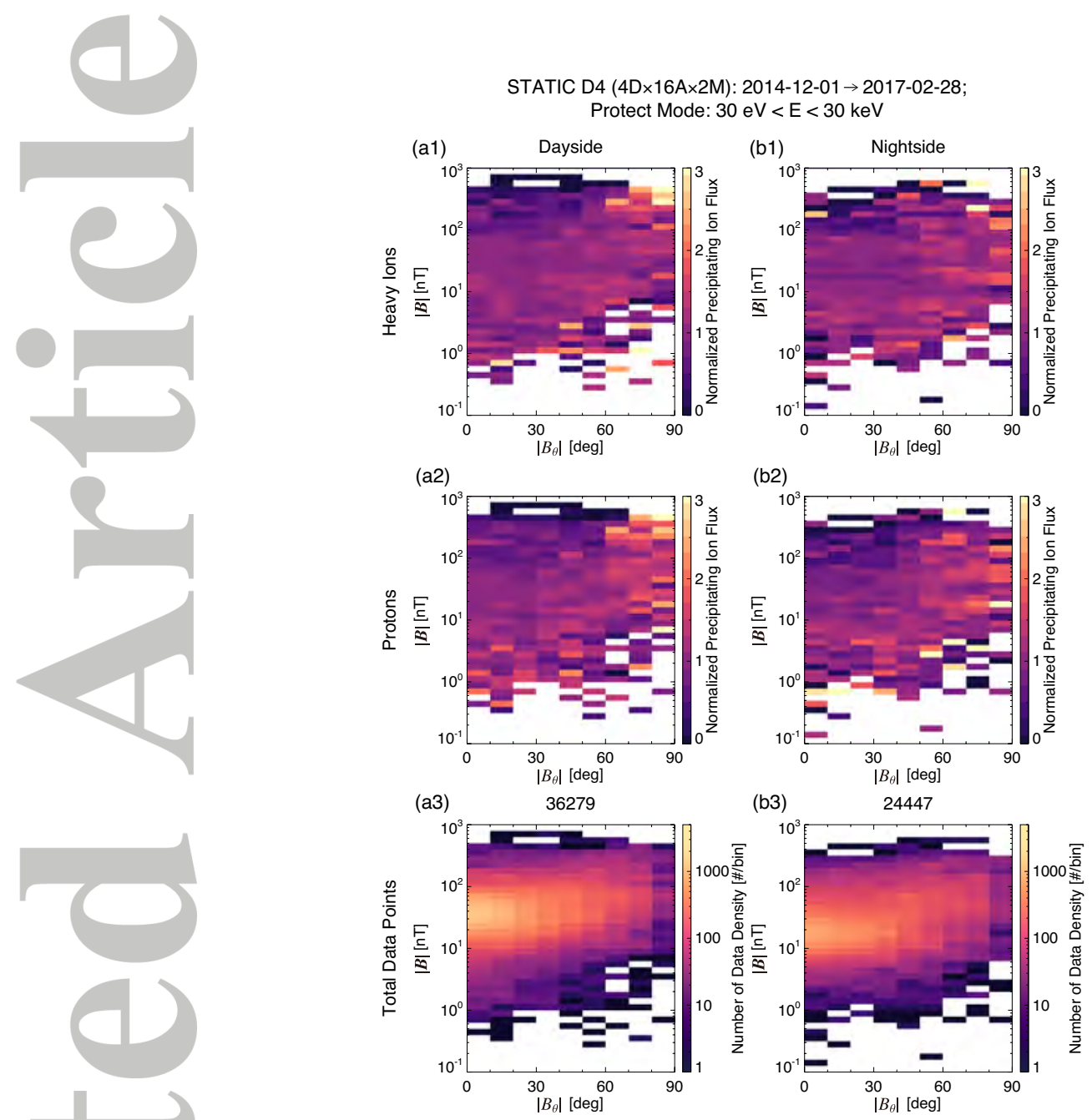

Figure 5. Statistical distributions of the normalized precipitating fluxes for (1: top) heavy ions and (2: center) protons, and of (3: bottom) the total number of the STATIC D4 data product, as a function of the absolute value of the local magnetic elevation angle $\left(\left|B_{\theta}\right|\right)$ and the total magnetic field strength $(|\boldsymbol{B}|)$ observed on (a) the dayside and (b) nightside, respectively. Total data points are shown at the top of Figures $5 \mathrm{a} 3$ and 5b3. Statistical distributions of the standard error of Figure 5 are shown in Figure S4 in the supporting information.

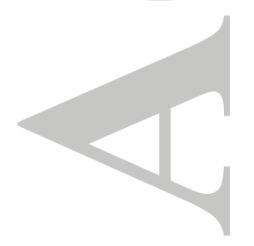

(C)2018 American Geophysical Union. All Rights Reserved. 

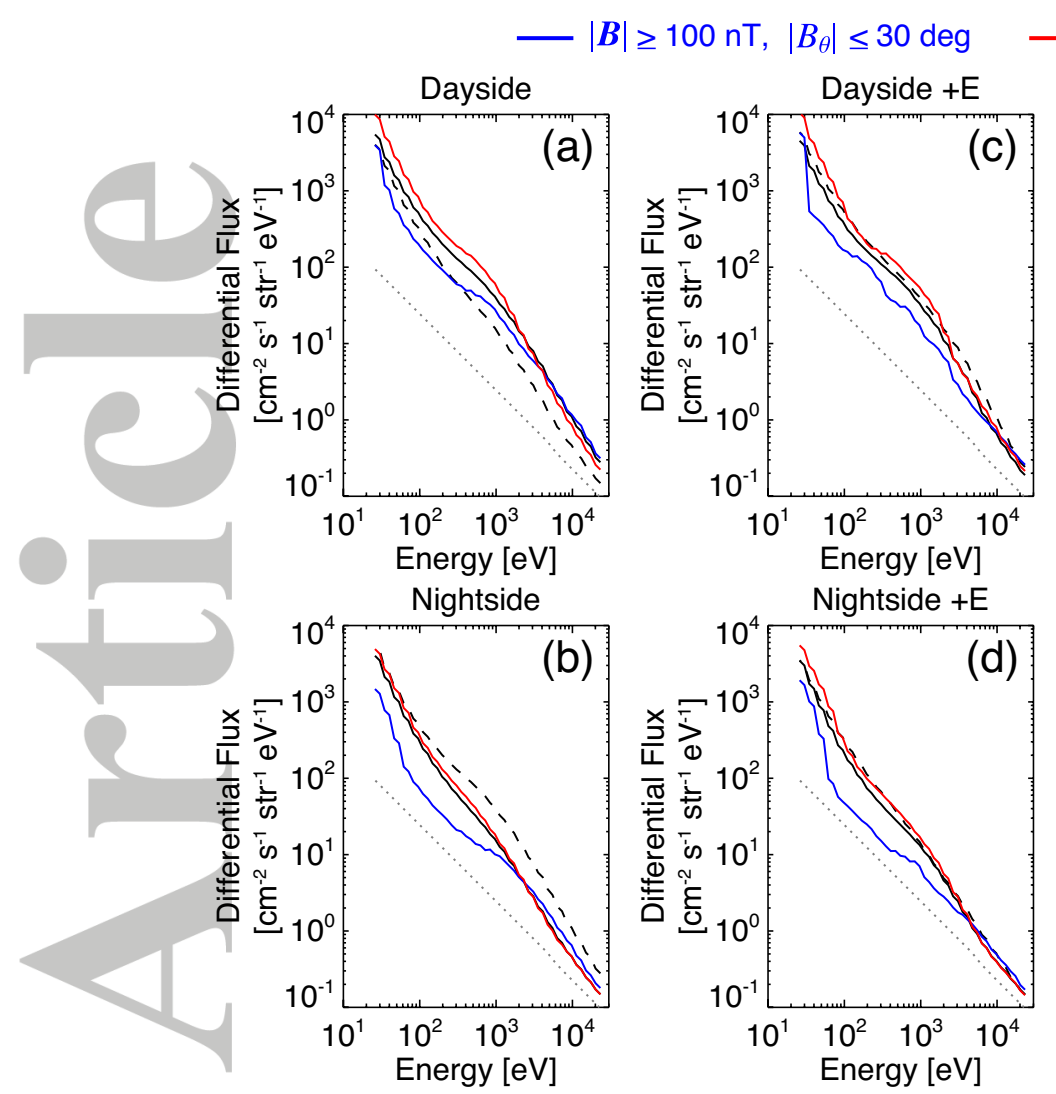

$-\left|B_{\theta}\right| \geq 60 \mathrm{deg}$
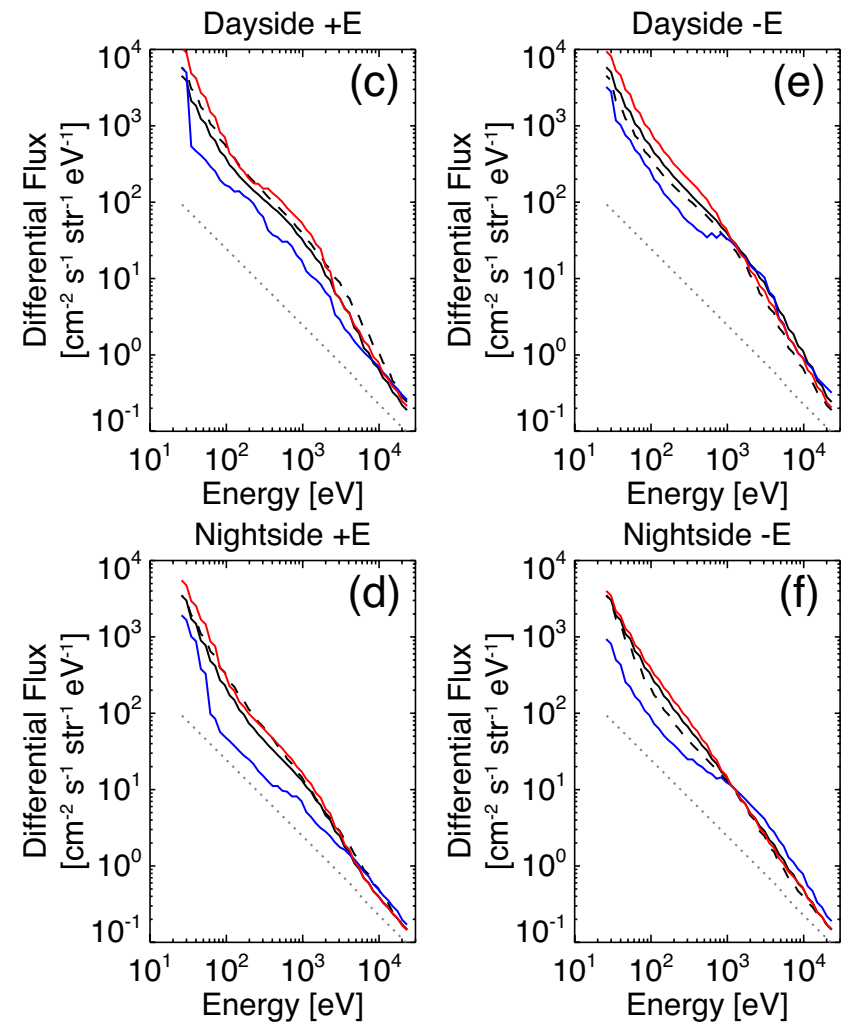

Figure 6. Average energy spectra (black solid lines) with respect to ions precipitating toward the Martian upper atmosphere in (a) the dayside, (b) the nightside, (c) the dayside $+\boldsymbol{E}$ hemisphere, (d) the nightside $+\boldsymbol{E}$ hemisphere, (e) the dayside $-\boldsymbol{E}$ hemisphere, (f) the nightside $-\boldsymbol{E}$ hemisphere, respectively. Blue solid spectra are those observed under the horizontal crustal magnetic field configurations $\left(\left|B_{\theta}\right| \leq 30^{\circ}\right)$ with strength stronger than $100 \mathrm{nT}$. Red solid spectra are those observed under the radial crustal magnetic field configurations $\left(\left|B_{\theta}\right| \geq 60^{\circ}\right)$ regardless of its field strength. Gray dotted spectra denotes the equivalent instrument one-count level. For comparisons, black dashed lines are energy spectra with respect to differential precipitating ion fluxes observed on (a) the nightside, (b) the dayside, (c) the dayside $-\boldsymbol{E}$ hemisphere, (d) the nightside $-\boldsymbol{E}$ hemisphere, (e) the dayside $+\boldsymbol{E}$ hemisphere, (f) the nightside $+\boldsymbol{E}$ hemisphere, respectively.

(C)2018 American Geophysical Union. All Rights Reserved. 


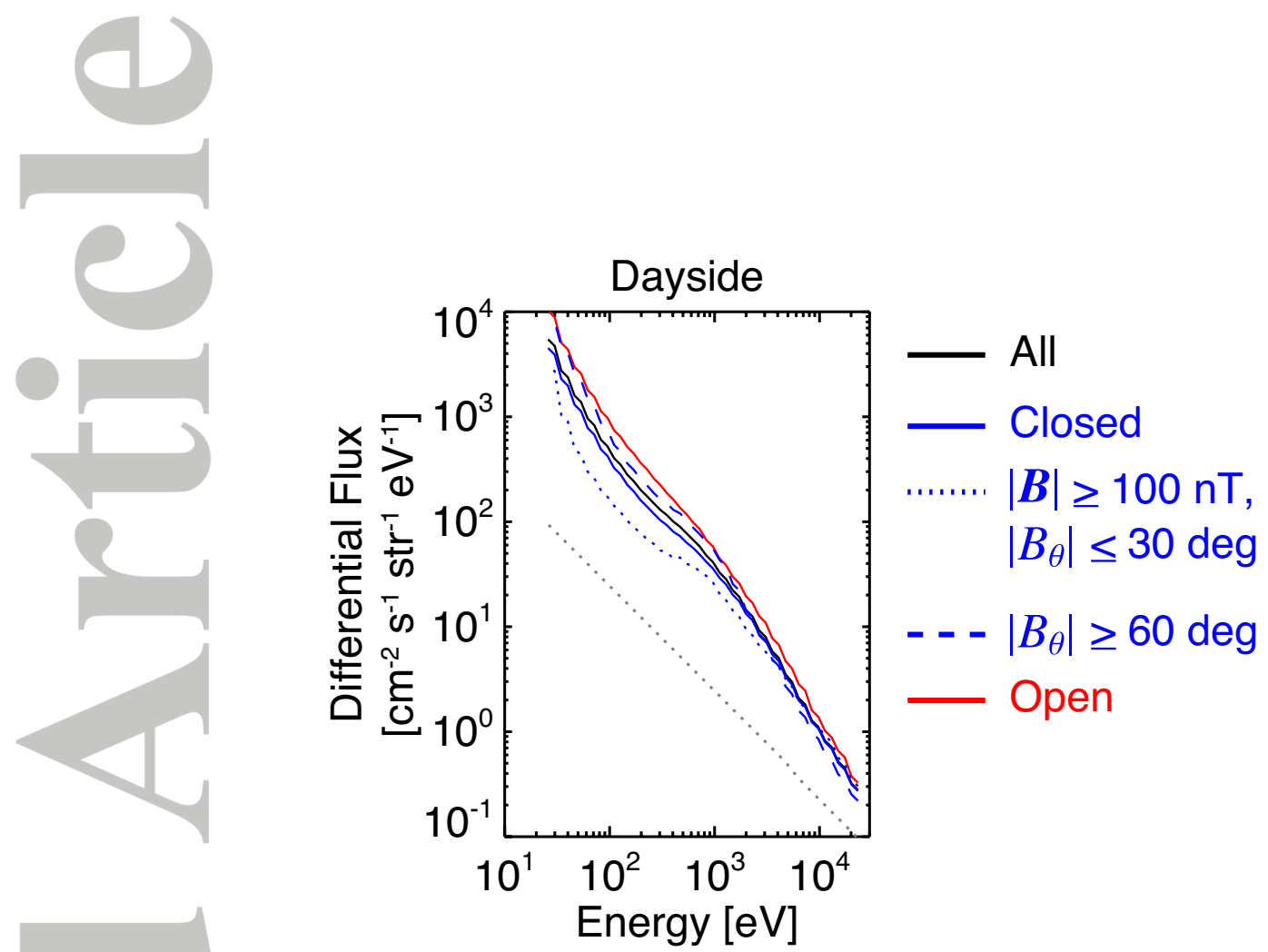

Figure 7. The energy spectra with respect to ions precipitating toward the Martian upper atmosphere in the dayside (black solid line), which is identical to the black solid line in Figure 6a. The blue (red) solid lines are that observed in the closed (open) field lines based on the SWEA electron shape parameter. The blue dotted and dashed lines are also those observed in the closed field lines; however, the local magnetic field is horizontal $\left(\left|B_{\theta}\right| \leq 30^{\circ}\right)$ with strength larger than $100 \mathrm{nT}$, and radial $\left(\left|B_{\theta}\right| \geq 60^{\circ}\right)$ regardless of its strength, respectively. The gray dotted line denotes the equivalent instrument one-count level.

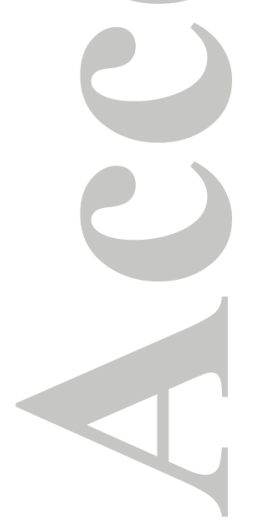




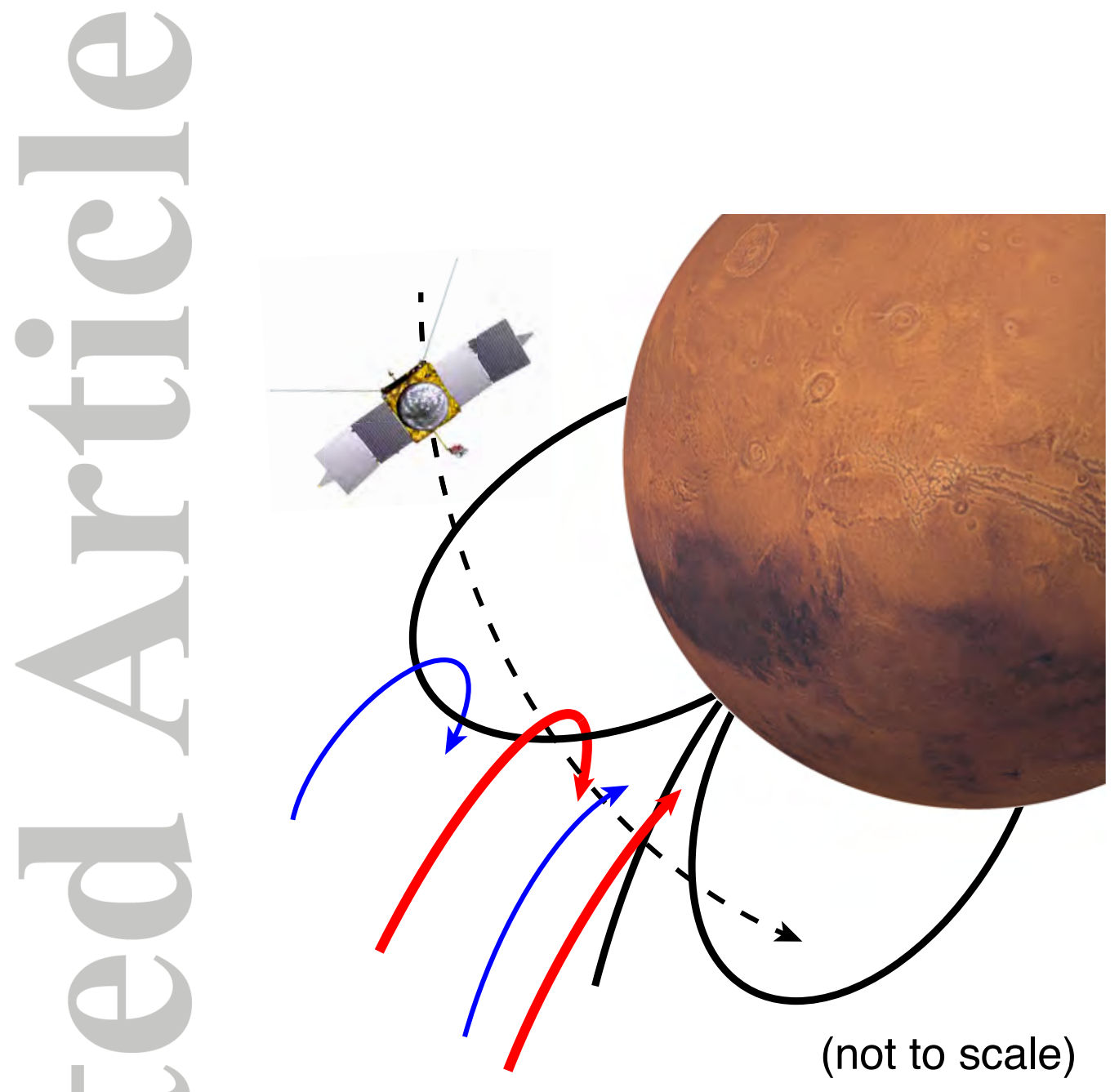

Figure 8. Schematic illustration of ions precipitating in the vicinity of the Martian crustal magnetic field. Black solid curves are crustal magnetic field lines. Black dashed arrow describes the spacecraft trajectory. Blue and red arrows are trajectories of low- and high- energy ions precipitating toward the Martian upper atmosphere.

(C)2018 American Geophysical Union. All Rights Reserved. 